\title{
Study on Deterioration Characteristics of Low-Carbon Steel's Mechanical Properties and Fracture Mechanism under Marine Engineering Environment
}

\author{
Lili Cao, ${ }^{1,2}$ Ming Li $\mathbb{D}^{2}$, Jiazhi Zhang, ${ }^{2}$ Gang Lin, ${ }^{2}$ Baichuan Gong, Xianbiao Mao, \\ Lianying Zhang, ${ }^{3}$ and Yan $\mathrm{Li} \mathbb{1}^{3}$ \\ ${ }^{1}$ School of Medical Information and Engineering, Xuzhou Medical University, Xuzhou 221004, Jiangsu, China \\ ${ }^{2}$ State Key Laboratory for Geomechanics and Deep Underground Engineering, China University of Mining and Technology, \\ Xuzhou 221116, Jiangsu, China \\ ${ }^{3}$ School of Civil Engineering, XuZhou University of Technology, Xuzhou 221018, Jiangsu, China
}

Correspondence should be addressed to Ming Li; mingl@cumt.edu.cn

Received 17 June 2021; Revised 30 July 2021; Accepted 23 August 2021; Published 8 October 2021

Academic Editor: Ragip Ince

Copyright $\odot 2021$ Lili Cao et al. This is an open access article distributed under the Creative Commons Attribution License, which permits unrestricted use, distribution, and reproduction in any medium, provided the original work is properly cited.

In order to study the mechanical properties of low-carbon steel under the coupling effect of the overall environment and the loads, the tensile mechanical test was carried out. The results indicated that, as the sea water concentration and tensile deterioration increased, both the mass-loss rate and surface roughness of the low-carbon steel gradually increased, and the yield strength, tensile strength, elongation, and section shrinkage decreased gradually. The mechanical parameters of the low-carbon steel were affected by the joint actions of the sea water concentration and tensile deterioration. The established mechanical model of low-carbon steel under the marine engineering environment shows that tensile deterioration had no effects on the fracture toughness, while the increase of sea water concentration could reduce the fracture toughness remarkably.

\section{Introduction}

Steel structures are main bearing carriers in multiple marine resource development and utilization engineering, such as cross-sea/offshore bridges, offshore oilfields, and ocean vessels. However, they are very prone to corrosion in the marine environment, resulting in the deterioration of mechanical properties. Eventually, the safety and reliability of the project will be greatly reduced. Therefore, it is of great significance to carry out the research on low-carbon steel's mechanical properties' change and degradation characteristics of its fracture toughness under the coupled action of corrosive environment and loads in marine engineering.

The change of surface properties before and after corrosion can directly reflect the corrosion degree of steel, which could provide references for the study on the effect of corrosion on mechanical properties of steel. With the technological progress, the observation can realized by means of optical microscopy and scanning electron microscopy (SEM) instead of naked-eye observation [1-3], indicating that the analysis of surface properties of steel has transformed from the macroscopic roughness to high-precision microscopic field. The pitting corrosion can develop into macroscopic cracks under conditions of local stress concentration and continuous corrosion and finally lead to complete failure of steel [4]. Thus, the corrosion defect size, morphology, and growth rate are points of concern in the macroimages and microimages through observation [5-7]. The change law of surface characteristics of steel under corrosion can be obtained by the qualitative analysis to some extent. The roughness scanning technique can be used for digital processing of surface characteristics and the analysis of specific parameters of corrosion defects of steel. Currently, more than 50 parameters are available through surface scanning, but they are not enough to describe a surface completely [8]. 
Degradation laws of mechanical properties of steel have been one of key research directions for steel corrosion problems in the marine environment. The related influencing factors have been widely studied, such as elements, compounds, and $\mathrm{pH}$ values. Zhang et al. studied the influence of niobium and rare Earth elements on the corrosion behavior of low-alloy steel bars and established the corresponding graphical models based on the experimental results [9]. Ma et al. studied the mechanisms of corrosion cracking of steel in the marine environment containing $\mathrm{SO}_{2}$ by electrochemical method and slow strain rate testing (SSRT) [10]. In order to simulate the marine environment more vividly, the corrosive environment considering the influence of microorganisms is increasingly used in experiments. Arun et al. studied microbial corrosion of steel by different types of welding processes [11]. Antony et al. studied the microbial corrosion of steel under different thermal aging conditions by making $\mathrm{NaC} 1$ containing bacterial media [12]. Meanwhile, with the development of corrosion resistance technology, research results have been made in the deterioration law of the mechanical and corrosion properties of steel under corrosion protection such as corrosion inhibitors and organic coatings. Wang et al. studied the effects of coral sand powder and corrosion inhibitors on reinforcement corrosion. They proposed and verified the time-varying model of steel corrosion [13]. Besides experimental studies, a series of mathematical algorithms and theoretical models have been developing gradually and becoming mature, which enriches the steel corrosion theory and provides theoretical supports for corrosion resistance [14]. At the same time, the theory-based numerical simulation can be built considering multiple environmental influencing factors to offer powerful references for actual engineering problems [15].

As one of the mechanical properties of measuring steel's ability to resist cracks and instability expansion, fracture toughness plays a critical role in industrial fields such as aerospace engineering, pressure vessels, and oil and gas pipeline transportation. In order to meet the requirements under different scenes, different processes are used to treat the steel, and the fracture toughness also varies [16-19]. In addition, the environment itself has significant effects on fracture toughness of steel. Especially, in the aerospace field, the fracture toughness performance has been a research hotspot in extremely harsh environments of outer space. $[20,21]$. However, most research studies focus on the deterioration of the tensile strength of low-carbon steel in the complex marine engineering environment, and the research of fracture toughness of steel is still rare [22].

At present, the basic theory of the corrosion of steel structure has been improved. The corrosion of the steel structure is the integration of corrosive media in the marine atmospheric environment. However, most research studies are about the single effect of certain corrosive media, while there are few studies on corrosion damage mechanisms of the steel structure under the coupling effect of the overall environment and the loads. Under such backgrounds, it is important to carry out the study on mechanical properties change and degradation characteristics of low-carbon steel before and after corrosion under the coupling effect of the load and complex marine environment. This is useful to renovate aseptic technique of ocean platform, increase the service life of steel structures, and save maintenance costs of marine facilities.

\section{Test Overview}

2.1. Sampling. Q345B steel was selected as the test material, whose main microelements and mass scores $(w)$ are shown in Table 1. It is low-alloy structural steel with high strength, comprehensive welding property, and sound machinability. It has been widely utilized in cross-sea bridges, ships, ports, etc. The conventional cylindrical tensile specimens were adopted out of homogeneous plates unaffected by corrosion or loads. The processed specimens were polished and became smooth by grinding the surface with a sandpaper. After the polishing, the residual grease and other contaminants were cleaned by using an ultrasonic cleaner. Figure 1 shows the prepared specimen and the size.

\subsection{Simulation System of the Marine Engineering Environment}

2.2.1. Composition of the Simulation System. Damage in steel structures is mainly caused by seawater corrosion and tensile stress for a long time in the marine engineering environment (hereinafter, called tensile strength deterioration). Therefore, their effects could be reflected by the testing system, as shown in Figure 2. It consists of the tensile system of sample corrosion and environmental control system. The former includes artificial sea water $(A)$, samples $(B)$, oxygen environment $(C)$, lever $(D)$, and counterweight $(E)$. The latter includes the temperature control system $(F)$, lighting system $(G)$, corrosion delivery system $(H)$, and oxygen delivery system $(I)$. In this system, the sample could be subjected to real-time sea water corrosion and continuous tensile strength. At the same time, it could provide necessary space environment with factors of temperature, $\mathrm{pH}$, light, and dissolved oxygen. The range of temperature control was between $00^{\circ} \mathrm{C}$ and $50^{\circ} \mathrm{C}$ with the control precision of $\pm 1^{\circ} \mathrm{C}$. The $\mathrm{pH}$ value ranged from 4 to 9 . The testing range of the dissolved oxygen was between $0 \mathrm{ppm}$ and $20 \mathrm{ppm}$.

2.2.2. Preparation of Artificial Seawater. The key of the simulation was to prepare artificial seawater. According to major components of natural seawater, three steps were used to prepare the seawater, as shown in Figure 3. The method of seawater configuration in [23] was adopted in this paper:

(1) To prepare basic solutions (Figure 3(a)), Solution 1 was prepared by dissolving $388.90 \mathrm{~g} \mathrm{MgCl}_{2} \cdot 6 \mathrm{H}_{2} \mathrm{O}$, $40.56 \mathrm{~g} \mathrm{CaCl}_{2}$, and $1.48 \mathrm{~g} \mathrm{SrCl}_{2} \cdot 6 \mathrm{H}_{2} \mathrm{O}$ into $500 \mathrm{~mL}$ distilled water and adding more water until final volume of $700 \mathrm{~mL}$. To dissolve the compounds of $48.62 \mathrm{~g}$ $\mathrm{KCl}_{2}, 14.07 \mathrm{~g} \mathrm{NaHCO}_{3}, 7.04 \mathrm{~g} \mathrm{KBr}, 1.90 \mathrm{~g} \mathrm{H}_{3} \mathrm{BO}_{3}$, and $0.21 \mathrm{~g} \mathrm{NaF}$ into $70 \mathrm{~mL}$ distilled water and diluted to $100 \mathrm{~mL}$, Solution 2 was prepared. Solution 3 was prepared by putting $24.54 \mathrm{~g} \mathrm{NaCl}$ and $4.09 \mathrm{~g} \mathrm{Na}_{2} \mathrm{SO}_{4}$ into a measuring cup of $500 \mathrm{~mL}$. 
TABLe 1: Microelements and mass scores $(w \%)$ in Q345 steel.

\begin{tabular}{lccccccccccc}
\hline Microelements & $\mathrm{C}$ & $\mathrm{Si}$ & $\mathrm{Mn}$ & $\mathrm{P}$ & $\mathrm{S}$ & $\mathrm{V}$ & $\mathrm{Nb}$ & $\mathrm{Ti}$ & $\mathrm{Cr}$ & $\mathrm{Ni}$ & $\mathrm{Cu}$ \\
\hline$w(\%)$ & 0.20 & 0.50 & 1.70 & 0.035 & 0.035 & 0.15 & 0.07 & 0.20 & 0.30 & 0.50 & 0.30 \\
\hline
\end{tabular}

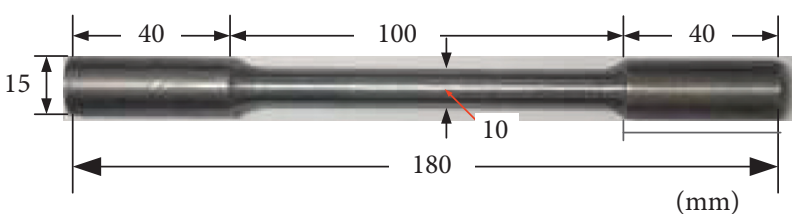

FIgURE 1: The prepared specimen.

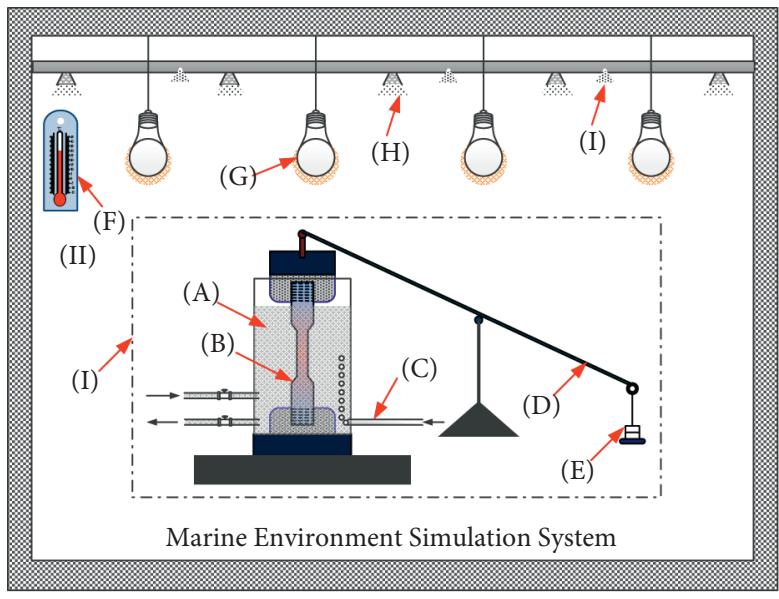

(a)

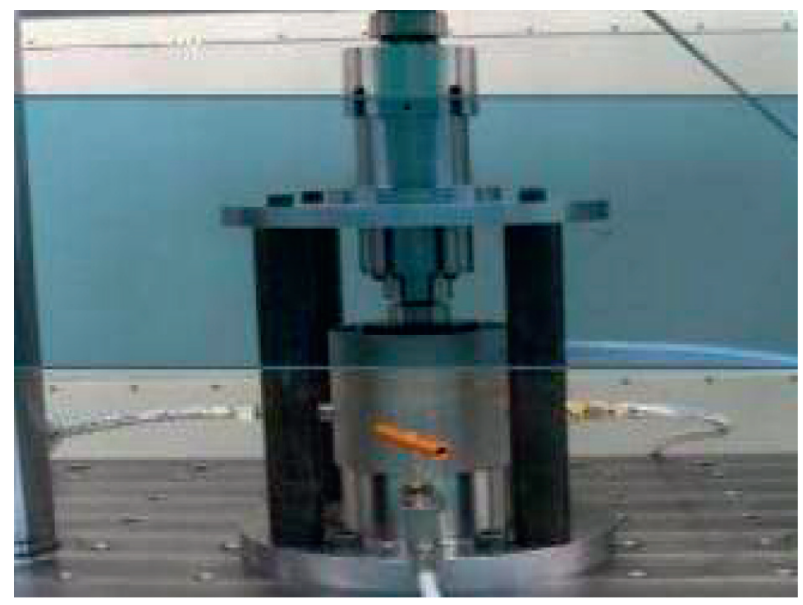

(b)

Figure 2: The simulation test system of the marine engineering environment. (a) (I. Tensile system of sample corrosion; II. environmental control system; (A) artificial sea water; (B) sample; (C) oxygen; (D) lever; (E) weights; (F) temperature control device; (G) ultraviolet radiator; (H) acid-base mist; (I) heavy-oxygen-enriched water). (b) Physical drawing of the test system.

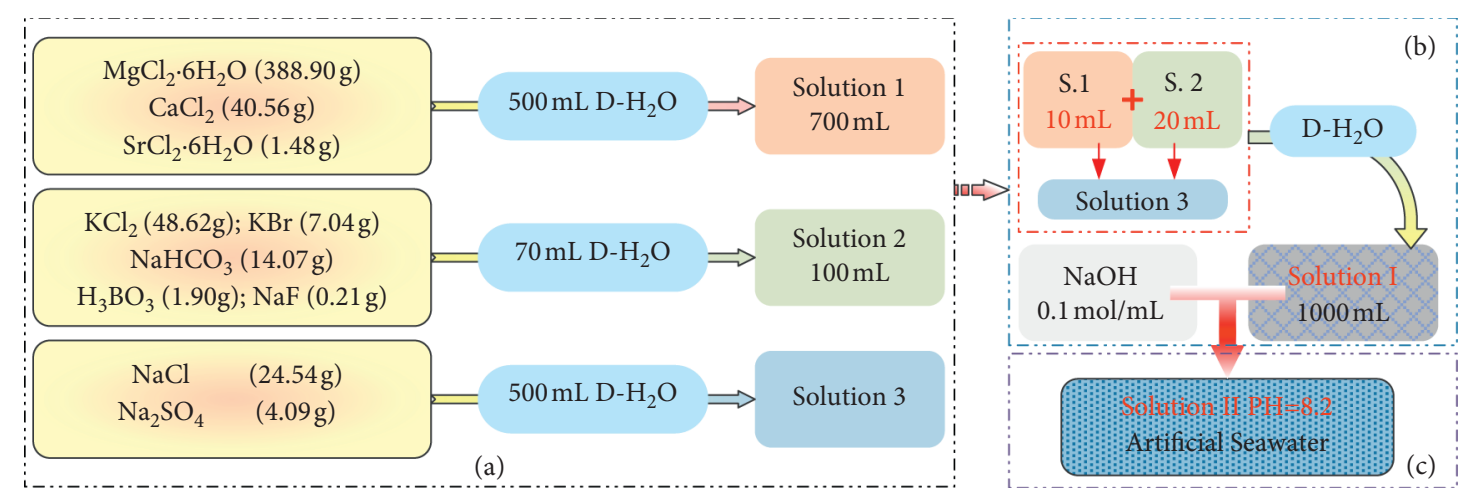

Figure 3: Preparation of artificial sea water. (a) Basic solution preparation. (b) Mixed solution preparation. (c). Artificial sea water preparation.

(2) To prepare mixed solutions (Figure 3(b)), $20 \mathrm{~mL}$ Solution 1 and $10 \mathrm{~mL}$ Solution 2 were added to Solution 3 and diluted to $1000 \mathrm{~mL}$. Thus, mixed Solution I was prepared.

(3) To prepare artificial sea water (Figure 3(c)), the artificial sea water was prepared by adding $0.1 \mathrm{~mol} / \mathrm{mL}$ $\mathrm{NaOH}$ solution to dilute Solution I until the $\mathrm{pH}$ value reached 8.2 .

\subsection{Testing Scheme and Method}

2.3.1. Environmental Control Scheme. The $\mathrm{pH}$ values of the sea water solution and environment were 8.2. The temperature in daytime was $30^{\circ} \mathrm{C}$ under ultraviolet light. The relative humidity was $40 \%$. The nighttime temperature was $10^{\circ} \mathrm{C}$ without UV light. Stable tensile loads were applied by increasing weights. Samples were taken out after placing samples for 100 days. 
2.3.2. Corrosion and Loading Scheme. Taking sea water concentration and tensile stress as variables, the orthogonal loading test was carried out to simulate the combined actions of corrosion and tensile deterioration. The mass scores $(c)$ of sea water solutes were set as $20 \%, 40 \%, 60 \%$, and $80 \%$. The tensile stress levels $\left(\sigma_{a}\right)$ were set as $0 \mathrm{MPa}, 80 \mathrm{MPa}, 160 \mathrm{MPa}$, and $240 \mathrm{MPa}$.

2.3.3. Test Process. The whole test was divided into three steps, as follows:

Firstly, the same batch of steel was selected to produce the samples. The surfaces of samples were polished and cleaned. Then, they were checked to make sure there were no cracks and oxide films.

Secondly, samples were installed in the simulation system of the marine engineering environment. Then, according to the requirements of the test scheme, sea water concentration and tensile stress were set. Next, the environmental parameters were set. Their effects lasted for 100 days.

Finally, samples were dried in the natural environment under the joint actions of corrosion and tensile deterioration. The Servo-Hydraulic Universal Testing Machine (CSUTM-HYD) was used for the tensile test to test the samples' mechanical properties, as shown in Figure 4.

In this test, there were 5 samples in each group under the effects of corrosion and tensile deterioration. Three to four samples were used for the final tensile test, and the remaining samples were used for the observation of surface corrosion characteristics.

\section{Performance of Surface Deterioration of Low-Carbon Steel in Marine Engineering Environment}

\subsection{Determination of Surface Characteristics and Deteriora-} tion Index. Figure 5 shows characteristics of sample surfaces under different environments. Compared with the original sample (Figure 5(a)), the surface of the sample subjected to sea water corrosion and tensile deterioration (Figure 5(b)) showed a remarkable corrosion state with lots of yellow rusts. After rust removal by the white vinegar, the surface color (Figure 5(c)) was darker than that of the original color. In order to more clearly observe the corrosive effects of sea water and continuous tensile stress on the sample, VHX$900 \mathrm{~F}$ super depth of field three-dimensional 200-fold microscope was used to observe the corrosive samples and samples after rust removal, thus getting surface characteristics of samples under various loading conditions, as shown in Figure 6.

Figure 6 indicated that the corrosive sample occurred lots of fine granular yellow substance on the surface. After removing the rust, a large number of pits could be observed on the surface. As the concentration of sea water increased, the volume of local granular substances gradually increased. The area of the pits also increased after removing the rust. The sample exhibited stronger roughness on the whole.

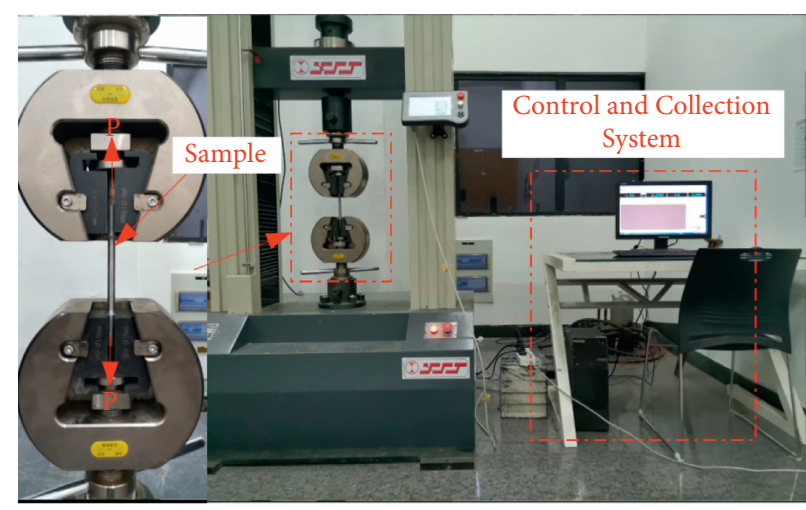

FIgURE 4: Tensile test system.

According to surface characteristics of samples and structural states, to implement quantitative analysis of corrosion characteristics, the mass-loss rate of the sample $(\lambda)$ and roughness $(R)$ were selected as cracking indexes of steel surface.

3.2. Mass-Loss Rate Change Characteristics. In this research, the mass-loss rate of the sample was defined as follows:

$$
\lambda=\frac{\Delta m}{m_{0} \times s \times t} \times 1000=\frac{m_{0}-m_{r}}{m_{0} \times s \times t} \times 1000,
$$

where $\lambda$ is the mass-loss rate, $\%, \Delta m$ refers to the loss of quality, $g, m_{0}$ points to the mass of the original sample (Figure 5(a)), $g, m_{r}$ refers to the sample mass after removal of all rust (Figure 5(c)), $g, s$ refers to the surface area of the sample, $\mathrm{cm}^{2}$, and $t$ refers to the time of corrosion, $d$.

Therefore, the mass-loss rate $\lambda$ refers to the percentage of mass loss of steel per square centimeter per day during the corrosion process. $m_{0}$ and $m_{r}$ were obtained by high-precision electronic balance.

Through calculation, the variation law of mass-loss rate $\lambda$ with the tensile deterioration level $\left(\sigma_{a}\right)$ and the concentration (c) could be obtained, as shown in Figure 7. It could be found that, as $\sigma_{a}$ and $c$ increased gradually, $\lambda$ also increased, indicating that the corrosion-caused mass loss gradually increased. In order to more vividly show the effects of $\sigma_{a}$ and $c$ on the mass-loss rate, the variation curves of $\lambda$ with the single variable were given in Figures 7 (b) and 7 (c). As the single variable gradually increased, the mass-loss rate also increased and showed linear change. In Figure 7(b), when $c$ was fixed, $\lambda$ increased slowly with the increase of $\sigma_{a}$. When $c$ were $20 \%, 40 \%, 60 \%$, and $80 \%$, the change amplitudes of $\lambda$ were $11.38 \%(2.90 \%$ o $\longrightarrow 3.23 \%$ ), $16.51 \%$ (3.21\%o $\longrightarrow 3.74 \%$ ), $12.37 \%$ (3.72\%o $\longrightarrow 4.18 \%$ ), and $9.33 \%$ $\left(4.50 \%\right.$ o $\longrightarrow 4.92 \%$ o), respectively. When $\sigma_{a}$ was fixed, $\lambda$ increased rapidly with the increase of $c$. When $c$ increased from $20 \%$ to $80 \%$, the increase rates of $\lambda$ exceeded $50 \%$, that is, $55.17 \%$ (2.90\% $\longrightarrow 4.50 \%$ o), $57.05 \%$ (2.98\%o $\longrightarrow 4.68 \%$ o), $54.69 \% \quad(309 \%$ o $\longrightarrow 4.78 \%$ o $)$, and $52.32 \% \quad(3.23 \%$ o $\longrightarrow$ $4.92 \%$ ), respectively. It can thus be seen that sea water corrosion was the major cause of mass loss of the sample under the combined actions of sea water and tensile 


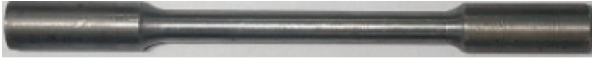

(a)

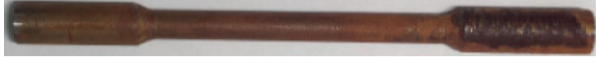

(b)

(c)

Figure 5: Samples under various test states. (a) The original sample. (b) The sample subjected to corrosion and tensile cracking. (c) The sample after rust removal.

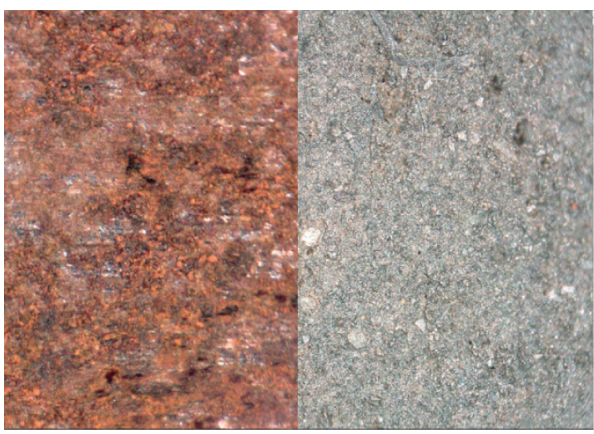

(a)

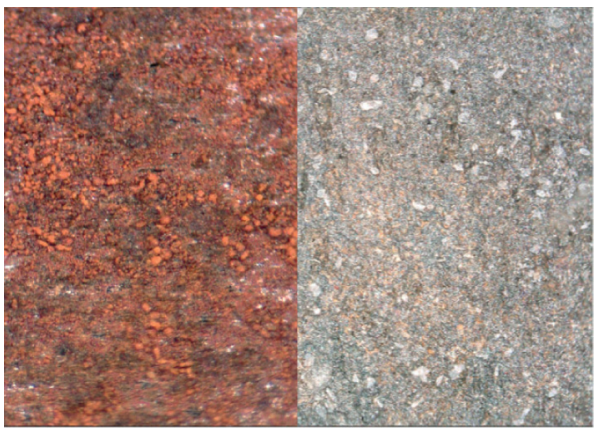

(c)

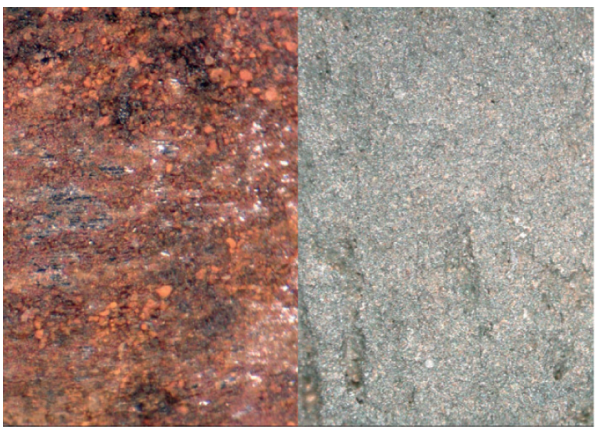

(b)

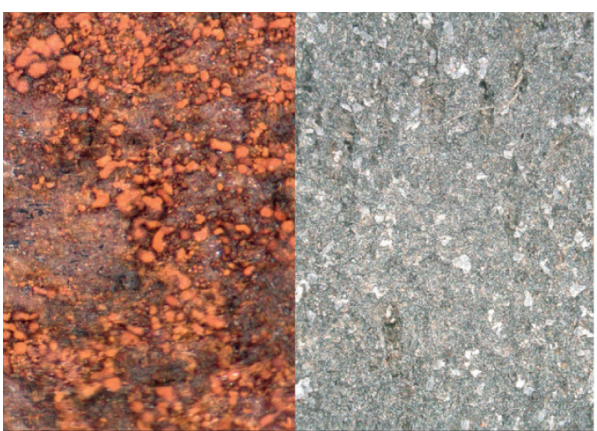

(d)

FIGURE 6: Local characteristics of the sample under the effects of corrosion and tensile deterioration (200-fold, some samples) (left: corrosive state; right: after rust removal). (a) $c=20 \%$ and $\sigma_{a}=0 \mathrm{MPa}$; (b) $c=40 \%$ and $\sigma_{a}=80 \mathrm{MPa}$; (c) $c=60 \%$ and $\sigma_{a}=160 \mathrm{MPa}$; (d) $c=80 \%$ and $\sigma_{a}=240 \mathrm{MPa}$.

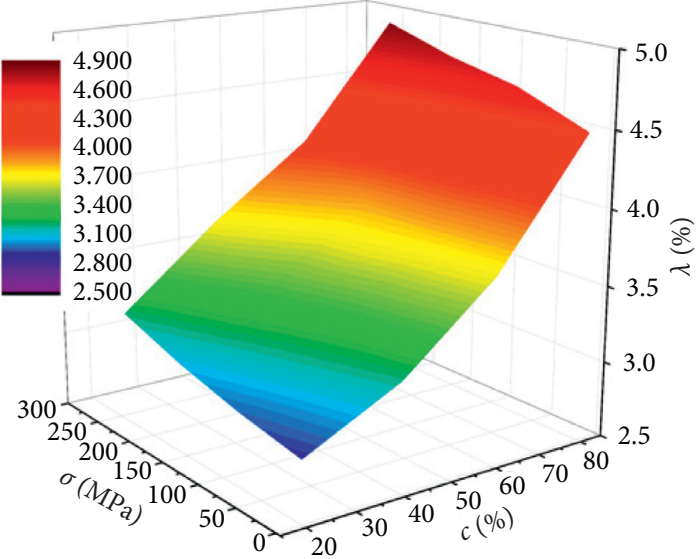

(a)

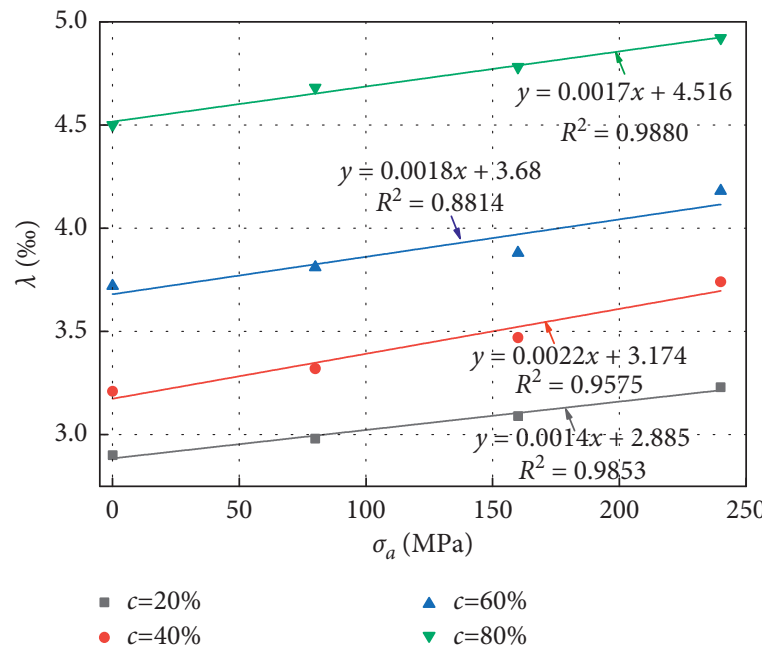

(b)

Figure 7: Continued. 


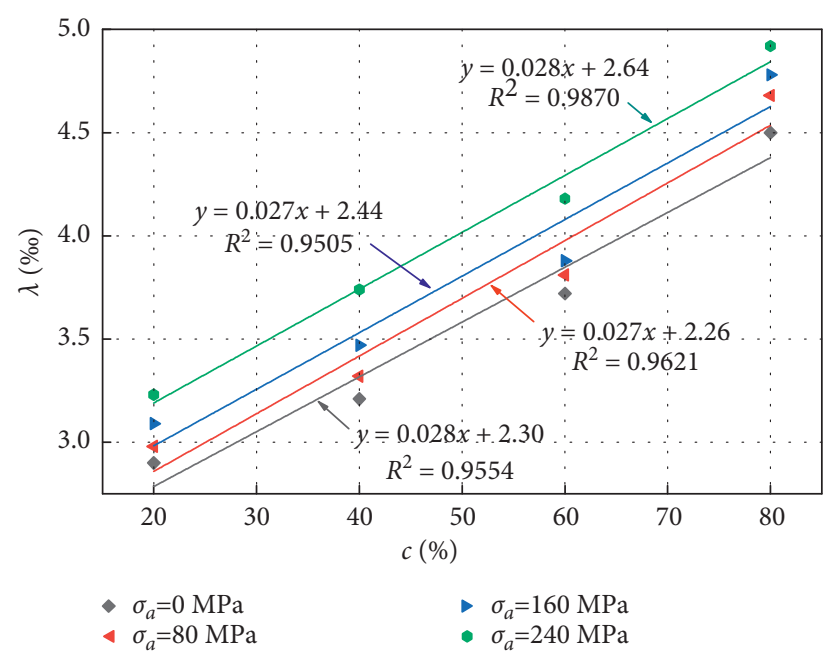

(c)

FIGURE 7: Variation laws of the mass-loss rate of the sample with the tensile deterioration $\sigma_{a}$ and seawater concentration. (a)Varying surface. (b) Tensile deterioration $\sigma_{a}$. (c) Concentration $c$.

deterioration. In Figures 7 (b) and 7(c), the straight slopes of $\lambda$ were basically the same under various conditions. It was indicated that there is no coupling effect on the mass loss of samples $\lambda$ under the combined action of seawater and tensile deterioration. In other words, seawater concentration and tensile deterioration level have no mutual influence on the mass loss of samples. In Figure $7(a)$, the whole curved surface approximates a plane. This is mainly due to the use of the homogeneous low-carbon steel material and the similar final results of the reaction between the material per area and alkaline substances in sea water in sufficient time, and external conditions are basically unrelated.

\subsection{Change Characteristics of Sample Surface Roughness}

3.3.1. Roughness Test Principles and Methods. The highresolution contactless $3 \mathrm{D}$ JR $3 \mathrm{D}$ scanning system was used to observe roughness characteristics of the sample surface. Raster was used, and the scanning accuracy could reach $0.015 \mathrm{~mm}$. Thus, the microstructure characteristics of the sample surface could be obtained accurately. Figure 8 shows the whole scanning process. The observation area was divided into grid cells by the scanning system, with coordinate values $\left\{\left(x_{i}, y_{j}, z_{i, j}\right),\left(x_{i+1}, y_{j}, z_{i+1, j}\right),\left(x_{i}, y_{j+1}, z_{i, j+1}\right),\left(x_{i+1}, y_{j+1}\right.\right.$, $\left.\left.z_{i+1, j+1}\right)\right\}$ of four corners of each cell. The whole surface of the tensile area in the middle of the sample was scanned to get data of the surface microstructure.

There are many roughness characterization methods. In this paper, the ratio of the actual area of the structural surface to the projected area proposed by EI-Soudani [24] was used to represent the roughness of the $3 \mathrm{D}$ fracture surface. The roughness coefficient $R_{s}$ is defined as follows:

$$
R_{s}=\frac{A_{r}}{A_{p}}
$$

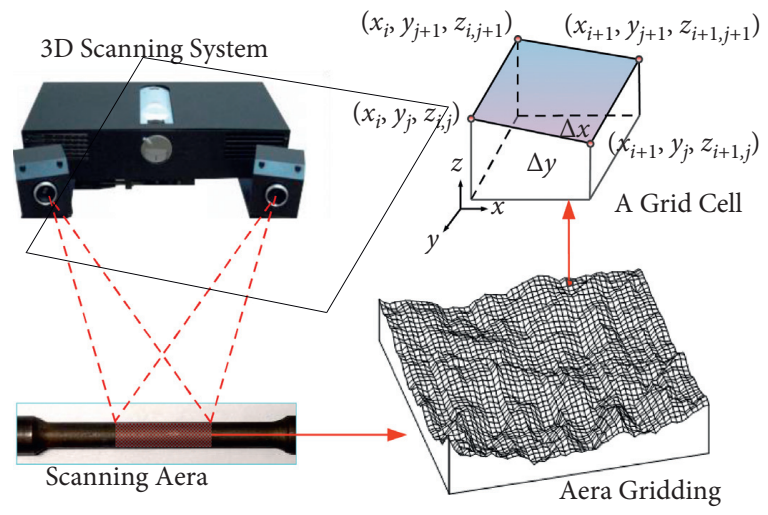

FIGURE 8: Test process of surface roughness.

where $A_{r}$ is the actual area of the structural surface, which can be calculated by grid cell coordinates and $A_{p}$ is the scan area, that is, the projection of $A_{r}$ in the scanning plane. It can be obtained by accumulating the areas.

The microcell plane in Figure 8 was taken as the research object. The points in the actual structural plane were continuous functions and were derivable. It is assumed that the coordinate of each point at the actual fracture surface follows a continuous differentiable function, so there is $z=(X, Y)$. The actual area $A_{r}$ could be calculated by integration, as follows:

$$
A_{r}=\int_{\text {surface }}\left[1+\left(\frac{\partial z}{\partial x}(x, y)\right)^{2}+\left(\frac{\partial z}{\partial y}(x, y)\right)^{2}\right]^{1 / 2} \mathrm{~d} x \mathrm{~d} y
$$

The actual area could be a superposition of each grid cell, and formula (3) could be transformed into formula (4), as follows: 


$$
A_{r} \approx(\Delta x \Delta y) \sum_{j=1}^{N y-1} \sum_{i=1}^{N x-1} \sqrt{1+\left(\frac{z_{i+1, j}-z_{i, j}}{\Delta x}\right)^{2}+\left(\frac{z_{i, j+1}-z_{i, j}}{\Delta y}\right)^{2}},
$$

where $z_{i, j}=f\left(x_{i}, y_{j}\right)$.

During the scanning process, each grid cell was square with $\Delta x=\Delta y$. With $\Delta x=\Delta y=\delta$, formula (4) can be changed into

$$
A_{r}=\delta^{2} \sum_{j=1}^{N y-1} \sum_{i=1}^{N x-1} \sqrt{1+\left(\frac{z_{i+1, j}-z_{i, j}}{\delta}\right)^{2}+\left(\frac{z_{i, j+1}-z_{i, j}}{\delta}\right)^{2}} .
$$

According to the resolution, $\delta$ and cell number $N$ could be determined during the scanning process. The output result was $z_{i, j}$. Then, $A_{r}$ could be solved by using formula (5). Based on formula (2), the roughness coefficient $R_{s}$ could be obtained under various conditions.

3.3.2. Variation Laws of Roughness. The roughness characteristics and coefficients of the sample surface were obtained through scanning test and calculation under various sea water concentration and tensile deterioration levels, as shown in Table 2. Figure 9 shows the varying surfaces and curves of roughness $R_{s}$ with the tensile deterioration level $\sigma_{a}$ and the sea water concentration $c$.

In Figure 9(a), with the increase of $c$ and $\sigma_{a}, R_{s}$ increased gradually, indicating that the degree of steel corrosion gradually increased under the effects of sea water and tensile deterioration. Figures 9 (b) and 9 (c) show the change law of $R_{s}$ with the single variable. It could be seen that, as $c$ or $\sigma_{a}$ increased, $R_{s}$ increased linearly. In contrast, the slope of the relation curve between $R_{s}$ and $c$ was larger, and thus, $c$ had greater impacts on corrosion of the sample surface. Specifically, $\sigma_{a}$ increased from $0 \mathrm{MPa}$ to $240 \mathrm{MPa}$. With $c$ of $20 \%, 40 \%, 60 \%$, and $80 \%, R_{s}$ increased by $2.40 \%, 2.32 \%$, $2.93 \%$, and $3.04 \%$, respectively. With $\sigma_{a}$ of $0 \mathrm{MPa}, 80 \mathrm{MPa}$, $160 \mathrm{MPa}$, and $240 \mathrm{MPa}, R_{s}$ increased by $4.25 \%, 4.45 \%$, $4.55 \%$, and $4.91 \%$, respectively. The straight slopes increased gradually with the increase of $R_{s}$ or $c$. It is indicated that sea water concentration and tensile deterioration level mutually increase the roughness of the sample surface, showing significant coupling effects. That is, sea water concentration and tensile deterioration level jointly affect the corrosion of the steel surface.

\section{Change Laws of Low-Carbon Steel Mechanical Properties under Marine Engineering Environment}

4.1. Tensile Stress-Strain Curve Change Characteristics of LowCarbon Steel Sample. Through the test, the tensile stressstrain curves and characteristic curves of the sample were obtained under various seawater concentration, and the tensile deterioration level was obtained, as shown in Figures 10(a)-10(e). Based on the characteristics of curves under various conditions, the tensile process of low-carbon steel experienced four stages, as follows:

Stage I (linear elastic stage of Segment ob (Figure 10(e)): there was a linear relationship between the stress and strain at this stage. As the strain increased, the stress increased rapidly in the linear form. The straight slope was the tensile modulus of lowcarbon steel. It was basically stable, around $210 \mathrm{GPa}$ through calculation, and thus, it was not analyzed separately.

Stage II (yield stage of Segment bd (Figure 10(e)): after the elastic stage, the low-carbon steel underwent the plastic deformation, and yielding was a special plastic deformation process. At this stage, the curve firstly went up, and then, the strain increased fast, while the stress fluctuated around a certain level. The minimum stress was the yield strength of the low-carbon steel, that is, $\sigma_{s}$.

Stage III (plastic hardening stage of Segment de): after undergoing the yield stage, the curve entered into the typical plastic deformation stage. As the strain continued to increase, the stress increased slowly and the slope decreased gradually until Point $e$, the peak, was reached. The corresponding stress was the tensile strength of the low-carbon steel, that is, $\sigma_{b}$.

Stage IV (unloading stage of Segment ef (Figure 10(e)): after reaching the peak height $e$, the stress dropped quickly with the increase of the strain and the lowcarbon steel reached the unloading stage. At this stage, the contractions were fast at the middle part of the sample, along with tensile fracture. Given the starting point of $f$, parallel to segment ob, and intersecting the horizontal axis at point $g$, the strain of Segment og $(\delta)$ was the elongation.

It could be found out that all curves underwent the abovementioned four stages. The differences among curves lied in the characteristic parameters, which will be analyzed in the following section.

4.2. Tensile Mechanical Parameters Change Characteristics of Low-Carbon Steel Sample. The tensile test of the low-carbon steel includes multiple elastic parameters. Among them, the yield strength $\sigma_{s}$ and the tensile strength $\sigma_{b}$ are obviously affected by the sea water concentration $c$ and the tensile deterioration level $\sigma_{a}$. Therefore, $\sigma_{s}$ and $\sigma_{b}$ were selected to analyze the mechanical properties of the low-carbon steel.

4.2.1. Change Law of the Yield Limit. Figure 11 shows the change law of $\sigma_{s}$ with $\sigma_{a}$ and $c$. In Figure 11(a), as $\sigma_{a}$ and $c$ increased, $\sigma_{s}$ decreased gradually. In order to analyze the change characteristics quantitatively, changes curves of $\sigma_{s}$ with $\sigma_{a}$ and $c$ were given, as shown in Figures 11(b) and 11(c). In Figure 11(b), $\sigma_{s}$ decreased fast in the linear form with the increase of the tensile stress under various sea water concentrations. $\sigma_{a}$ increased from 0 to $240 \mathrm{MPa}$. Under four kinds of concentrations, $\sigma_{s}$ decreased from $404.12 \mathrm{MPa}$, 
TABLE 2: Roughness characteristics of the sample surface under various loading conditions.

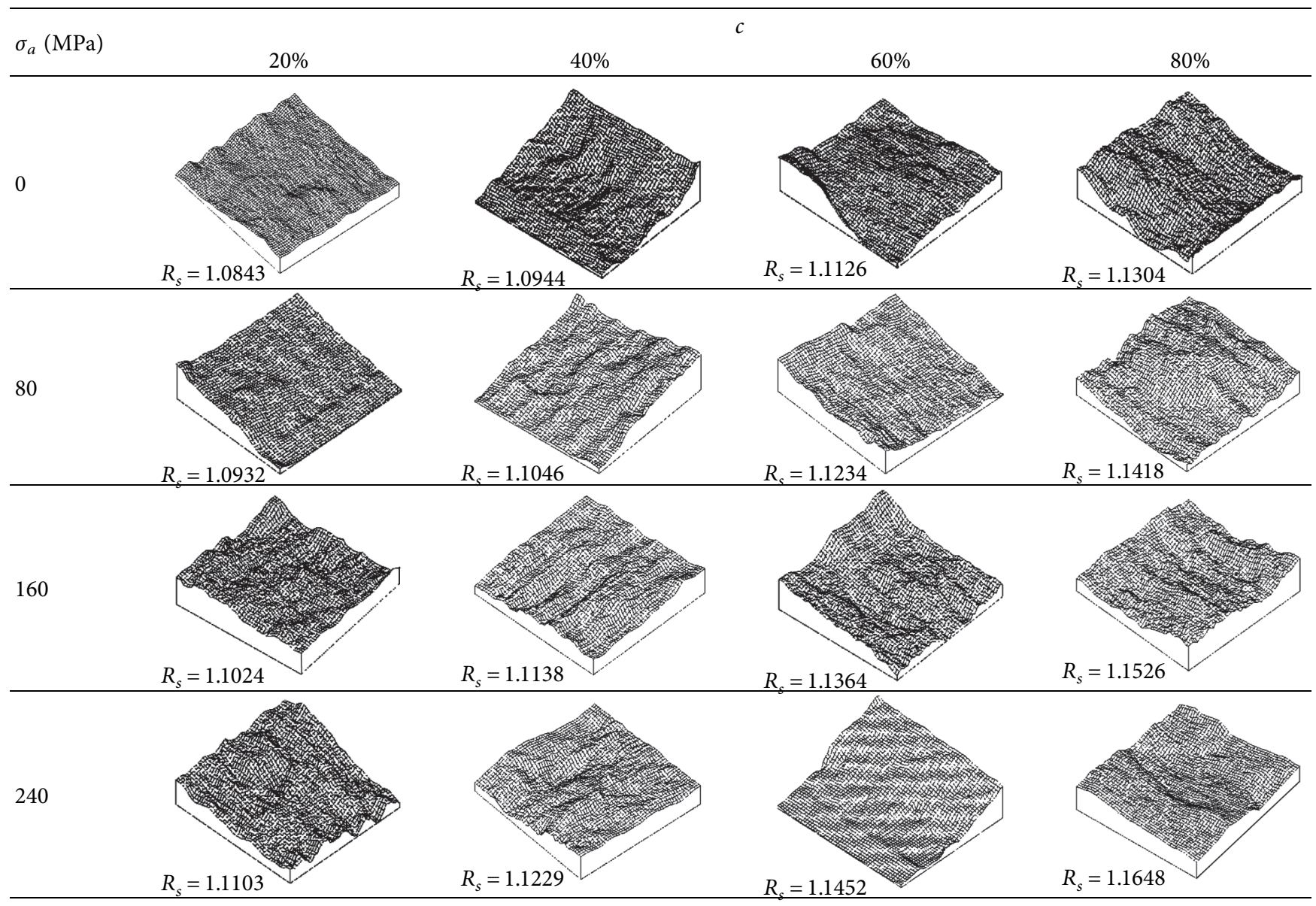

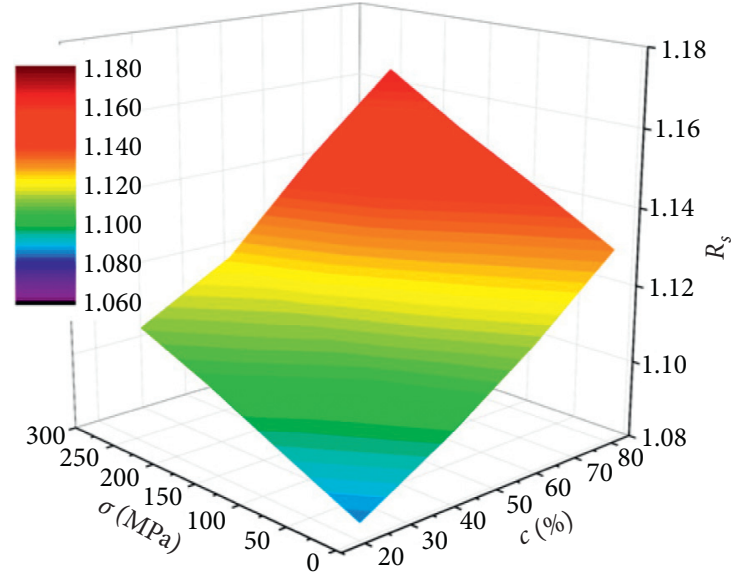

(a)

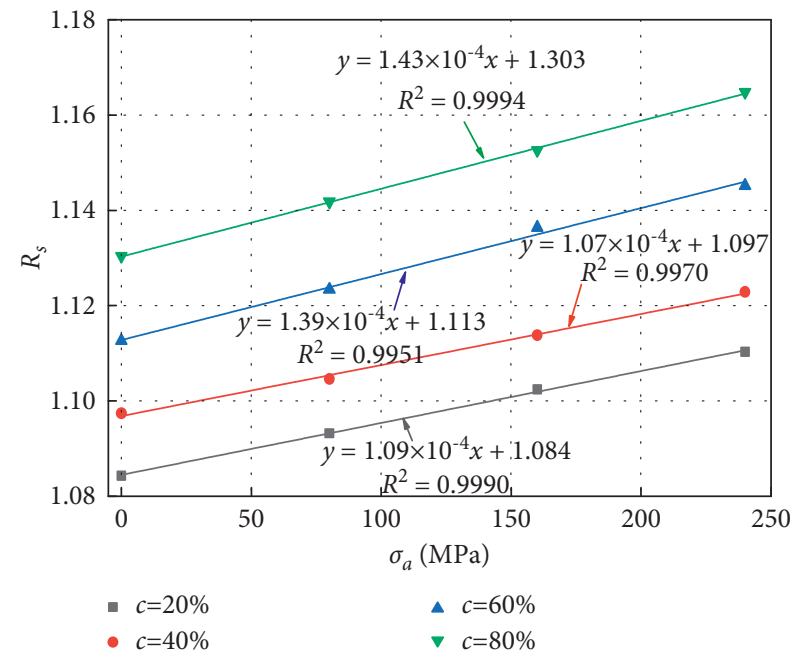

(b)

Figure 9: Continued. 


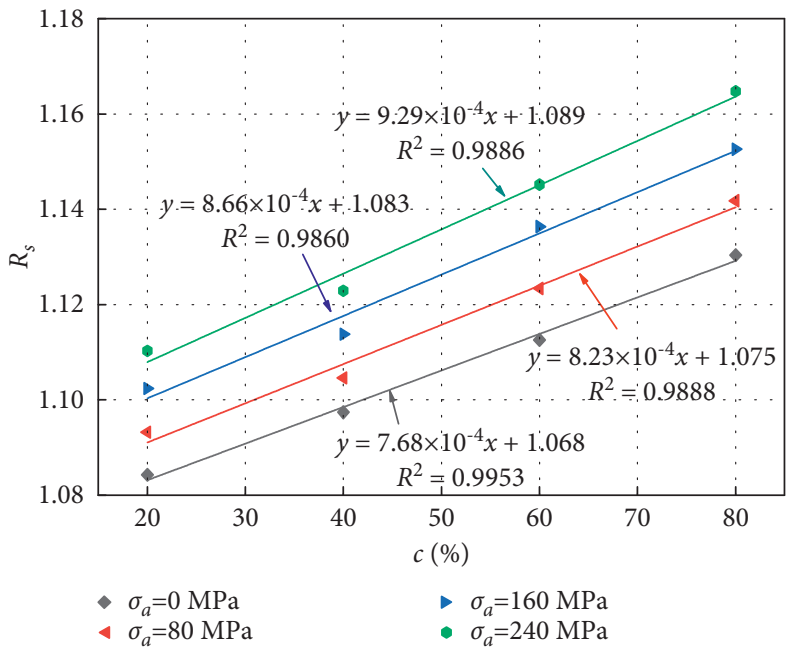

(c)

FigURE 9: Variation laws of surface roughness with tensile deterioration $\sigma_{a}$ and concentration. (a) Varying surface. (b) Tensile deterioration $\sigma_{a}$. (c) Seawater concentration $c$.

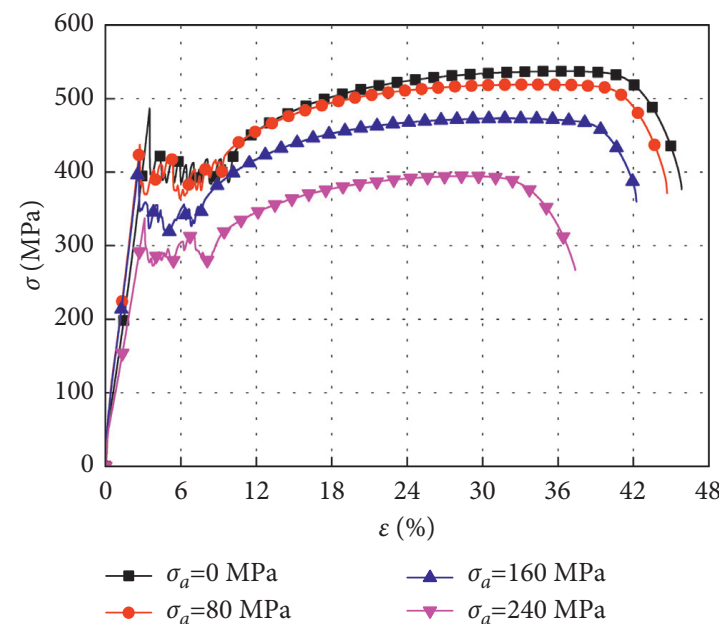

(a)

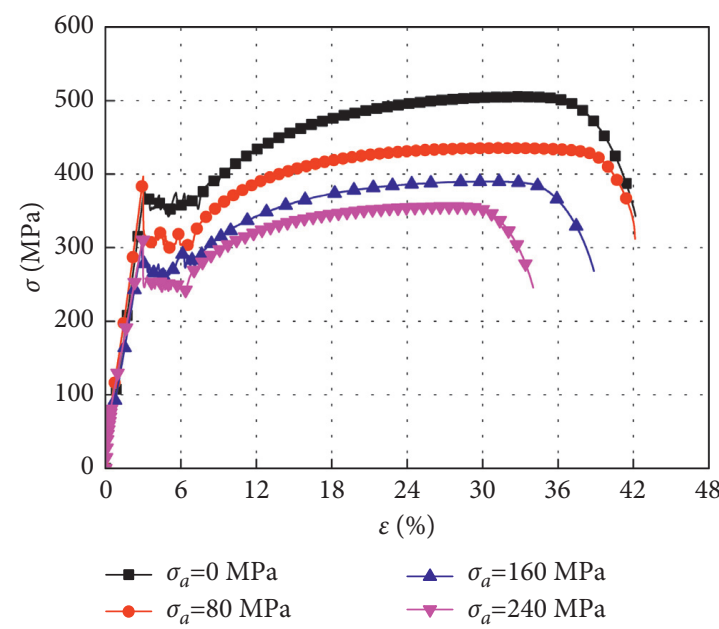

(c)

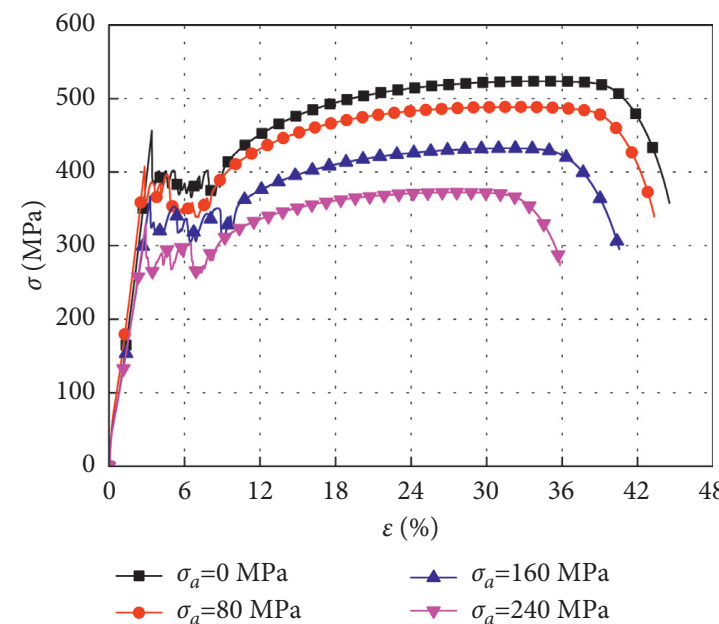

(b)

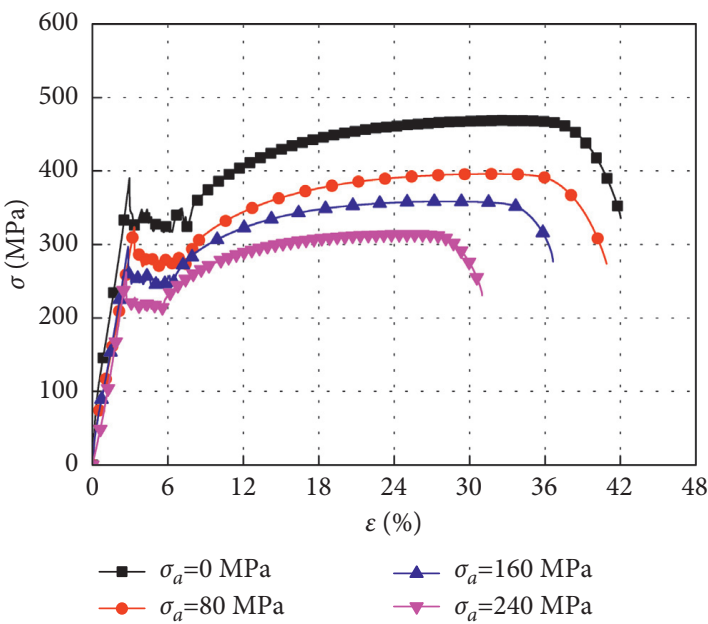

(d)

Figure 10: Continued. 


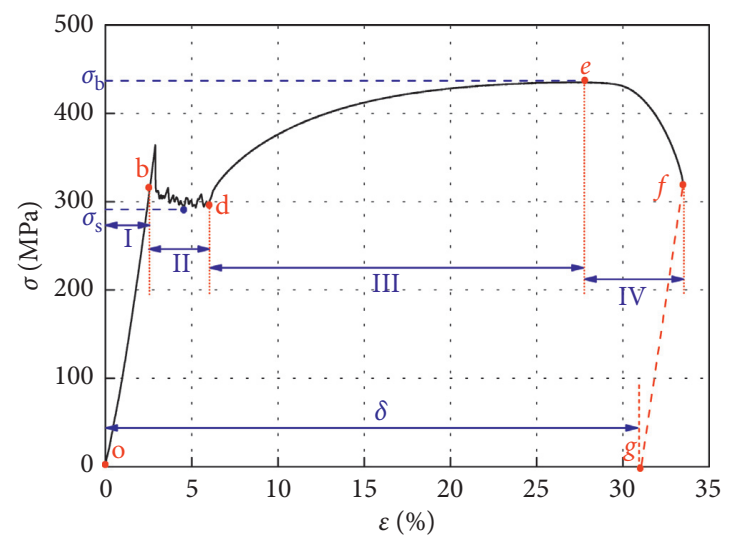

(e)

Figure 10: Tensile stress-strain curves of samples under various loading conditions. (a) $c=20 \%$. (b) $c=40 \%$. (c) $c=60 \%$. (d) $c=80 \%$. (e) Characteristic curves.

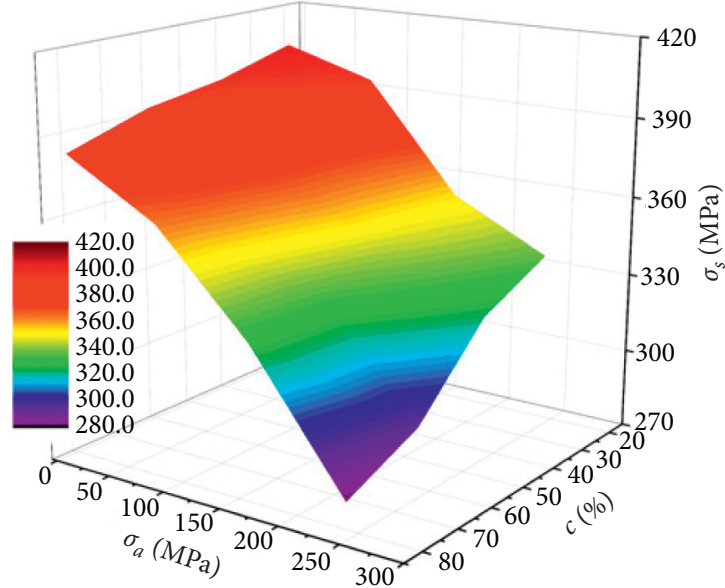

(a)

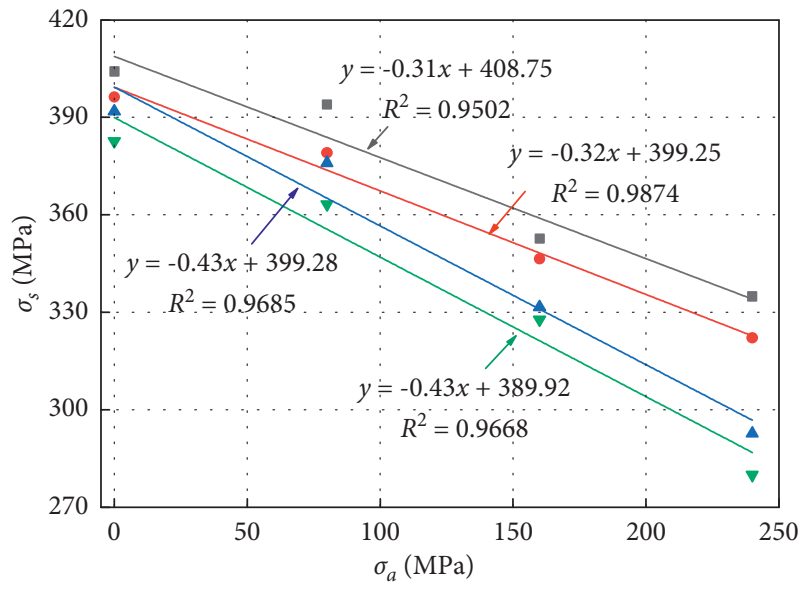

- $c=20 \%$

- $c=40 \%$
\ $c=60 \%$

$\nabla c=80 \%$

(b)

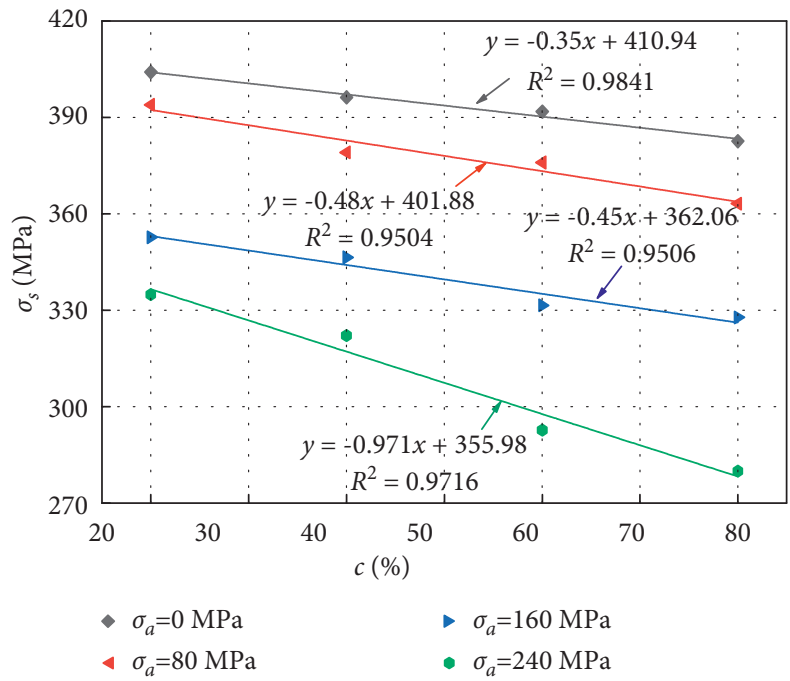

(c)

Figure 11: Variation law of yield limit $\sigma_{s}$ with tensile deterioration $\sigma_{a}$ and sea water concentration. (a) Varying surface. (b) Tensile deterioration $\sigma_{a}$. (c) Sea water concentration $c$. 
396.27 MPa, $391.84 \mathrm{MPa}$, and $382.63 \mathrm{MPa}$ to $334.87 \mathrm{MPa}$, $322.15 \mathrm{MPa}, 292.76 \mathrm{MPa}$, and $292.76 \mathrm{MPa}$, respectively, with amplitudes of $17.14 \%, 18.70 \%, 25.29 \%$, and $26.84 \%$. In Figure 11(c), the change law of $\sigma_{s}$ with $c$ was similar to that of $\sigma_{s}$ with $\sigma_{a}$. With $c$ increasing from $20 \%$ to $80 \%$ and four kinds of $\sigma_{a}, \sigma_{s}$ decreased from $404.12 \mathrm{MPa}, 393.92 \mathrm{MPa}$, $352.72 \mathrm{MPa}$, and $334.87 \mathrm{MPa}$ to $382.63 \mathrm{MPa}, 363.21 \mathrm{MPa}$, $327.77 \mathrm{MPa}$, and $279.93 \mathrm{MPa}$, respectively, with amplitudes of $5.32 \%, 7.80 \%, 7.07 \%$, and $16.41 \%$. It could found out that $\sigma_{a}$ had stronger influences on $\sigma_{s}$, which was different from cracking response characteristics of the low-carbon steel surface. In addition, the comparison among four straight lines in Figures 11(b) and 11(c) showed that, as $c$ or $\sigma_{a}$ increased, the straight slope gradually increased, indicating that the variation amplitude of $\sigma_{s}$ and its sensitivity to loading conditions increased gradually. $c$ or $\sigma_{a}$ had weakening effects on $\sigma_{s}$ of low-carbon steel.

4.2.2. Variation Law of Tensile Strength. According to tensile stress-strain curves, the variation laws of tensile strength $\sigma_{b}$ of low-carbon steel with the tensile deterioration $\sigma_{a}$ and sea water concentration $c$ could be obtained, as shown in Figure 12. It could be used to find out that whether the varying surface or the change curves and the low-carbon steel's response characteristics towards $\sigma_{a}$ and $c$ were similar to those towards the yield limit. As $\sigma_{a}$ and $c$ increased, $\sigma_{b}$ decreased rapidly in the linear form. As shown in Figure 12(b), with $\sigma_{a}$ increasing from 0 to $240 \mathrm{MPa}$ and four kinds of $c, \sigma_{b}$ decreased by $26.52 \%, 28.90 \%, 27.73 \%$, and $33.10 \%$, respectively. In Figure 12(c), with $c$ increasing from $20 \%$ to $80 \%$ and four kinds of stresses, $\sigma_{b}$ decreased by $12.72 \%, 3.74 \%, 24.17 \%$, and $20.55 \%$, respectively. The change characteristics of two groups of curves showed that the impact of $\sigma_{a}$ on $\sigma_{b}$ was greater than that of $c$.

The internal lattice of the low-carbon steel occurred dislocations due to long-term actions of tensile stress. Besides the effects of sea water corrosion, both the yield strength and tensile strength of the low-carbon steel tended to decrease.

4.3. Parametric Variation Characteristics of Tensile Deformation of Low-Carbon Steel Sample. The increase in length along the tensile direction and the shrinkage of the tensile section will be A process of the low-carbon steel sample. The elongation $\delta$ and section shrinkage $\psi$ were used to represent the tensile deformation. Their calculation methods are given, as follows:

$$
\delta=\frac{l_{1}-l_{0}}{l_{0}} \times 100 \%,
$$

where $l_{1}$ is the length of the sample after loading and $l_{0}$ is the length of the sample before loading:

$$
\psi=\frac{A_{0}-A_{1}}{A_{0}} \times 100 \%,
$$

where $A_{0}$ is the original cross-sectional area of the sample and $A_{1}$ is cross-sectional area after the load failure.
4.3.1. Change Law of the Elongation. According to formula (6), the varying surfaces and curves of the elongation $\delta$ with the tensile deterioration $\sigma_{a}$ and the sea water concentration $c$ were obtained by measuring dimensions of the sample before and after the tensile test, as shown in Figure 13. In Figure $13(\mathrm{a}), \delta$ was between $28 \%$ and $42 \%$, and the span reached $14 \%$. The deformation of the low-carbon steel was severely affected by $\sigma_{a}$ and $c$. As $\sigma_{a}$ and $c$ increased, $\delta$ gradually decreased. In Figures 13(b) and 13(c), there were linear relationships among $\delta, \sigma_{a}$, and $c$. In Figure 13(b), with $\sigma_{a}$ increasing from 0 to $240 \mathrm{MPa}$ and four kinds of concentrations, $\sigma_{b}$ decreased by $18.45 \%, 19.50 \%, 21.36 \%$, and $26.21 \%$, respectively. In Figure 13(c), with $c$ increasing from $20 \%$ to $80 \%$, and four kinds of $\sigma_{a}, \sigma_{b}$ decreased by $8.34 \%, 8.43 \%, 13.76 \%$, and $17.07 \%$, respectively. It could obtained that the early tensile stress had larger effects on the limit deformation of the low-carbon steel. Additionally, the slopes of two groups of straight lines showed that $\sigma_{a}$ and $c$ had weakening effects on $\delta$.

4.3.2. Variation Law of Section Shrinkage. Figure 14 shows the variation characteristics of section shrinkage $\psi$ with the tensile deterioration $\sigma_{a}$ and sea water concentration $c$ after tensile failure of the sample. In Figure 14(a), as the tensile stress and $c$ increased, $\psi$ gradually decreased and dropped rapidly under certain conditions. The difference between the maximum $\left(\sigma_{a}=0 \mathrm{MPa} ; c=20 \%\right)$ and the minimum $\left(\sigma_{a}=240 \mathrm{MPa} ; c=80 \%\right)$ was approximately $50 \%$. The joint effects of early tensile stress loading and sea water corrosion played a significant role in section shrinkage of the lowcarbon steel. Their effects were analyzed separately. In Figure 14(b), there was a negative exponential relationship between $\psi$ and $\sigma_{a}$. As $\sigma_{a}$ increased, $\psi$ decreased gradually. As $\sigma_{a}$ increased from $0 \mathrm{MPa}$ to $160 \mathrm{MPa}$, the amplitudes of shrinkage variation were relatively small. Under four kinds of $c$, they decreased by $4.51 \%, 4.98 \%, 5.94 \%$, and $17.70 \%$, respectively. However, when $\sigma_{a}$ increased from $160 \mathrm{MPa}$ to $240 \mathrm{MPa}$, they decreased by $11.48 \%, 21.52 \%, 35.95 \%$, and $51.69 \%$, respectively. In Figure 14(c), as $c$ increased, $\psi$ decreased fast in a linear form. Under four kinds of tensile stresses, $c$ increased from $20 \%$ to $80 \%$, and $\psi$ decreased by $4.99 \%, 4.78 \%, 18.11 \%$, and $55.30 \%$, respectively.

Change characteristics of the elongation and section shrinkage of the low-carbon steel indicated that the plastic deformation of the low-carbon steel gradually decreased under the joint actions of the early tensile stress and sea water corrosion. The properties of plastic were weakened and deteriorated. This is mainly because the arrangement of lattice in the steel was changed under long-term effects of tensile stress and seawater corrosion. Thus, the service life of the low-carbon steel is much shorter than that under the conventional environment.

\section{Tensile Fracture Toughness Analysis of Low-Carbon Steel under Marine Engineering Environment}

5.1. Model Establishment and Simplification. According to surface corrosion characteristics of the low-carbon steel sample under the effects of sea water and tensile 


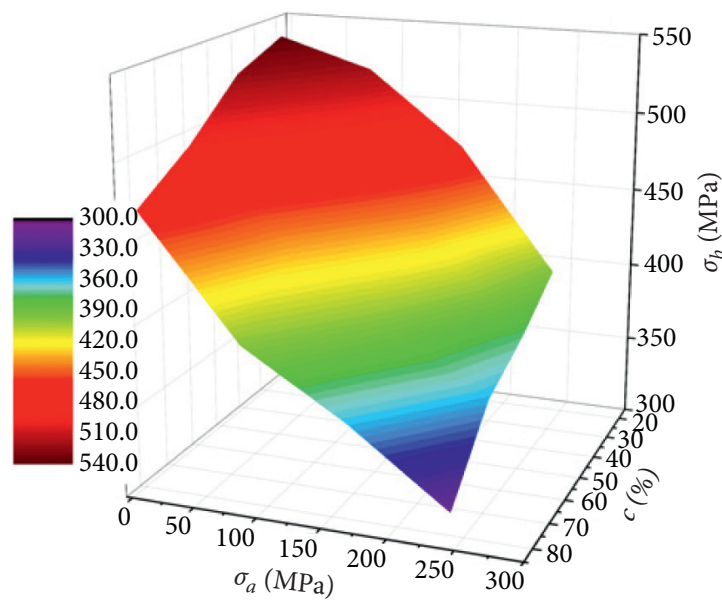

(a)

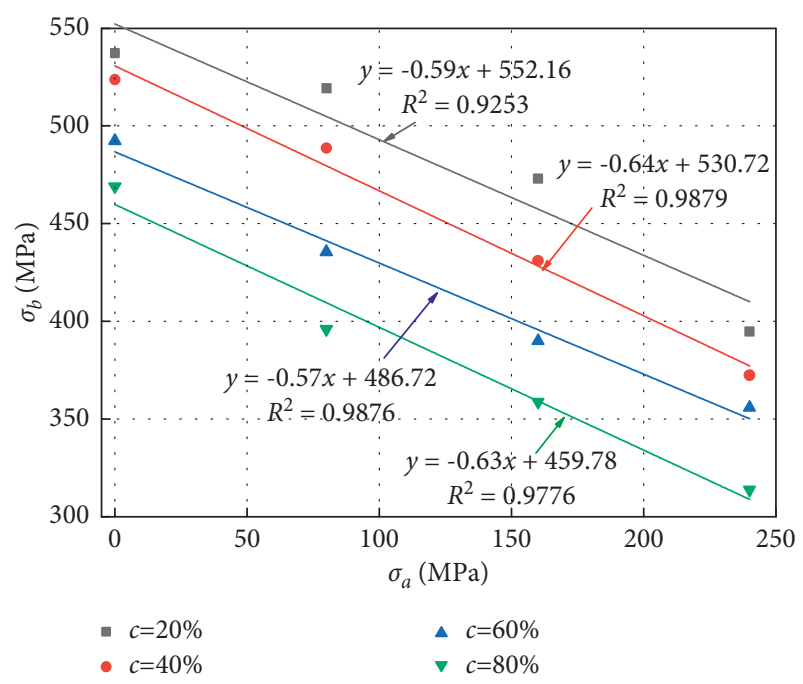

(b)

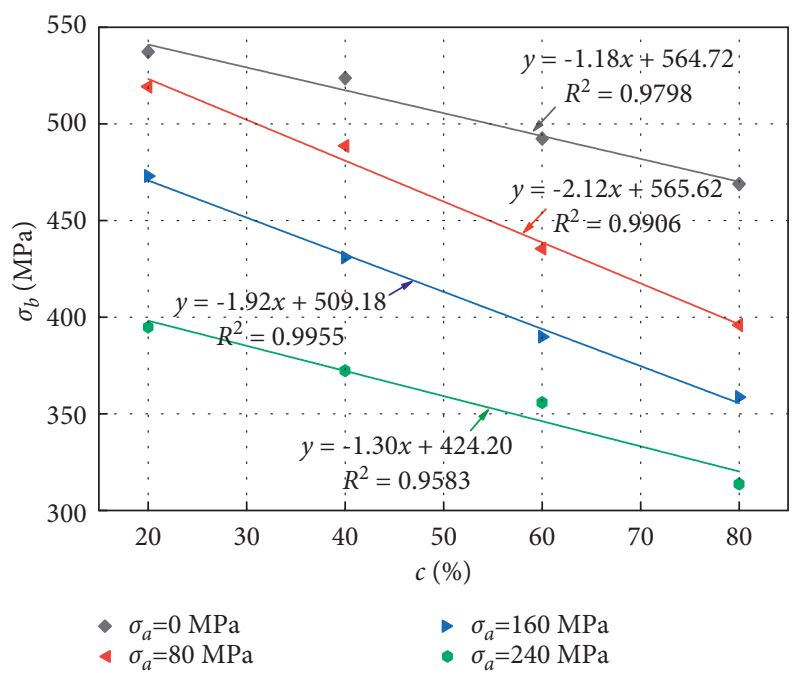

(c)

Figure 12: Variation laws of the tensile strength $\sigma_{b}$ with the tensile deterioration $\sigma_{a}$ and sea water concentration. (a) Varying curved surfaces. (b) Tensile deterioration $\sigma_{a}$. (c) Sea water concentration $c$.

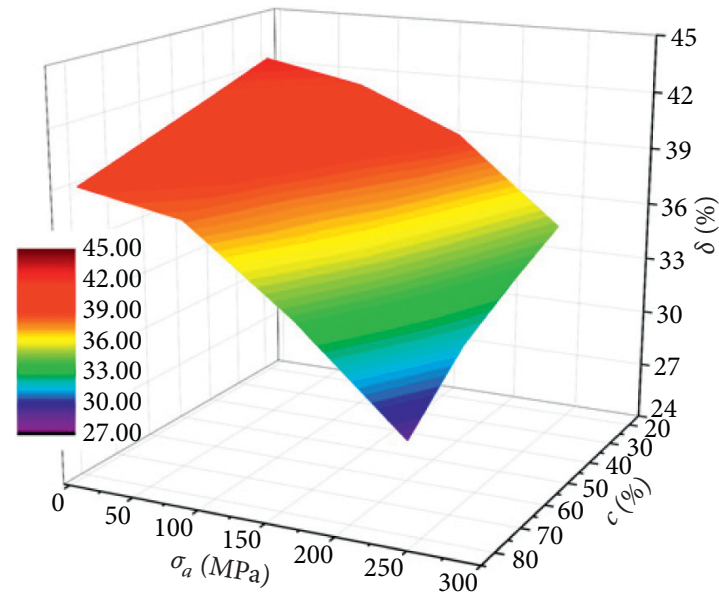

(a)

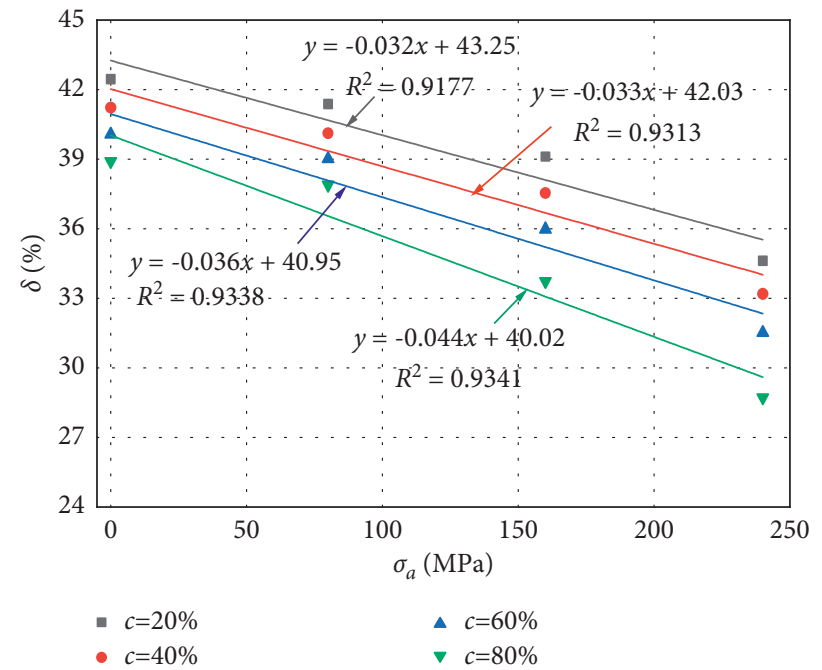

(b)

Figure 13: Continued. 


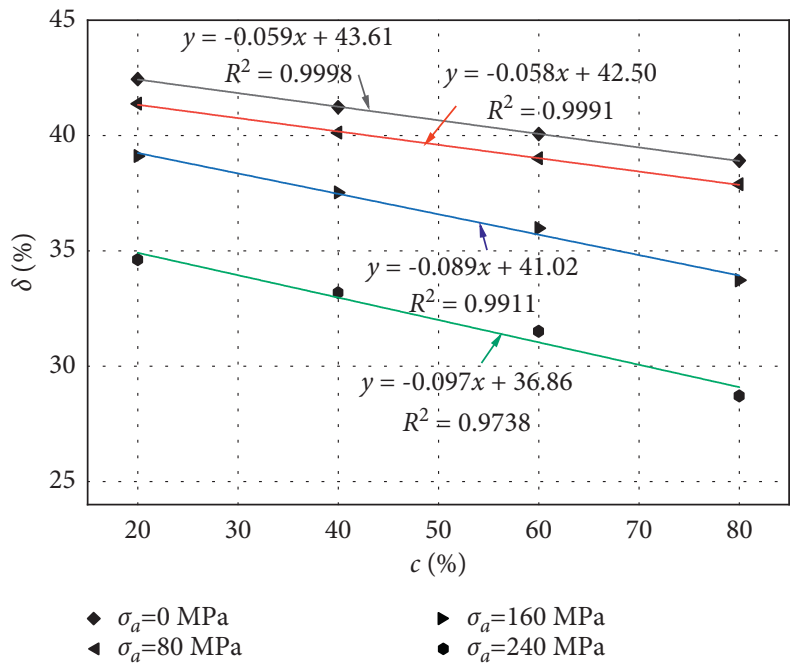

(c)

FIgURE 13: Variation law of the elongation $\delta$ with the tensile deterioration $\sigma_{a}$ and sea water concentration. (a) Varying surfaces. (b) Tensile deterioration $\sigma_{a}$. (c) Sea water concentration $c$.

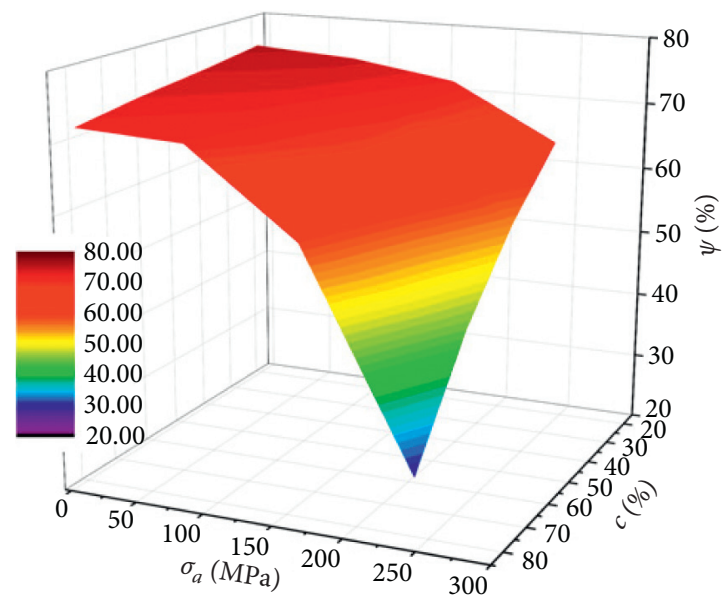

(a)

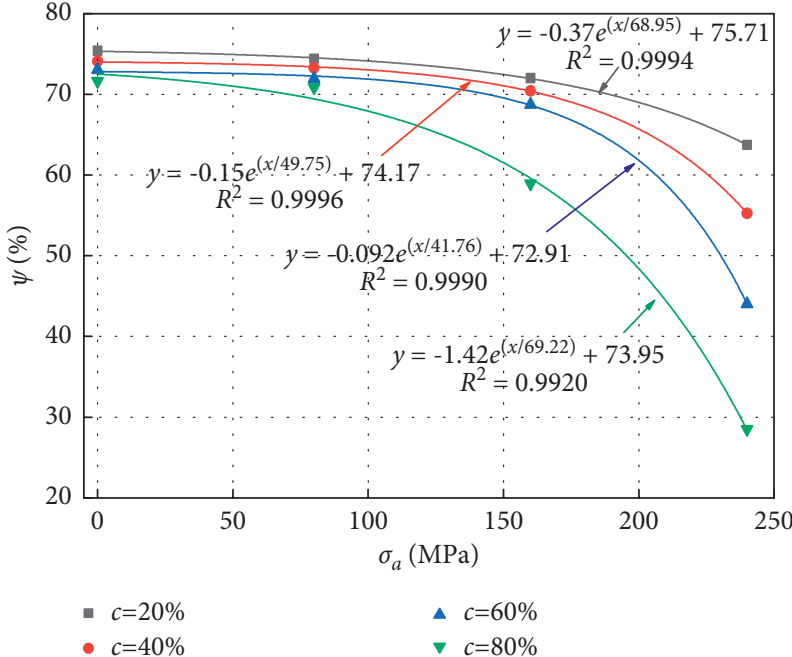

(b)

FIGURE 14: Continued. 


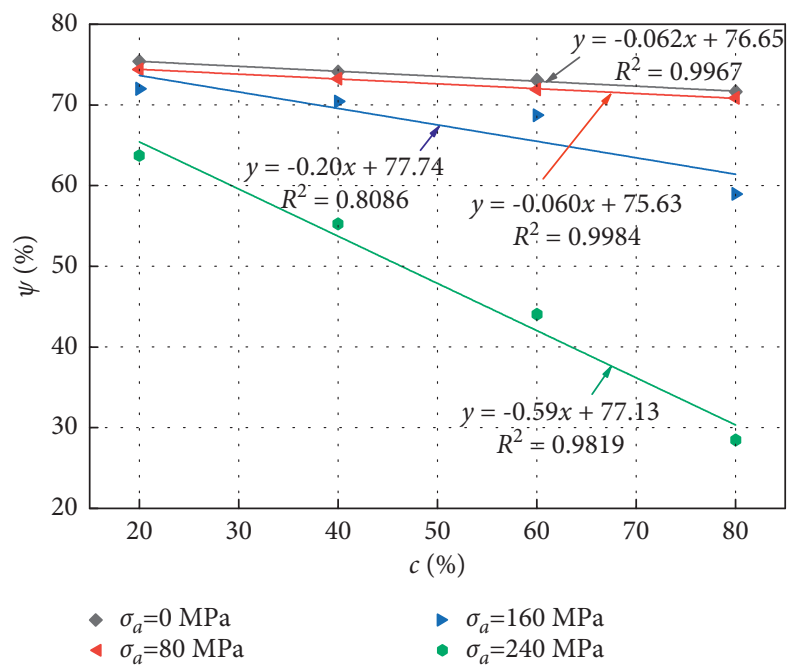

(c)

FIgURE 14: Variation laws of section shrinkage $\psi$ with tensile deterioration $\sigma_{a}$ and concentration. (a) Varying surfaces. (b) Tensile deterioration $\sigma_{a}$. (c) Sea water concentration $c$.

deterioration and behaviors during the tensile test, three assumptions were given for the tensile fracture process of low-carbon steel, as follows:

Assumption 1. Under the actions of sea water corrosion and tensile stress, the surface corrosion pits are distributed uniformly, and their shapes and dimensions are basically the same.

Assumption 2. In case of tensile failure of the low-carbon steel, the fracture surface is a plane and the positions of crack initiation are at the bottom of the pits.

Assumption 3. In case of tensile failure of the low-carbon steel, the pits around the fracture surface are distributed uniformly, and there is crack propagation.

Based on the aforementioned three assumptions, the mechanical analysis model of tensile failure of the lowcarbon steel was established, as shown in Figure 15(a). In the figure, $L$ is the length of the sample, which is $180 \mathrm{~mm}, R$ is the radius of the sample, which is $5 \mathrm{~mm}, \sigma$ refers to the stress during the tensile process, $\sigma_{b}$ is the tensile strength during crack growth, $a$ is the depth of the corrosion pit, and $d$ is the diameter of the corrosion pit.

The depth $a$ and the diameter $d$ of the pit could be obtained through the roughness test. According to the test results, $d / L \leq 10^{-3}$. According to the assumptions, the model in Figure 15(a) could be simplified as a strip of infinite length and width of $2 R$. Meanwhile, a pair of double edge cracks existed with the length of $a$, which could bear uniformlydistributed tensile stress $\sigma$ at an infinite distance, as shown in Figure 15(b).

The mechanical model in Figure 15(b) is a typical Type I crack growth model, that is, the single crack growth model. According to the linear elastic fracture mechanics, the stress field at any point $(r, \theta)$ at the crack tip $(a \longrightarrow 0)$ could be expressed as follows:

$$
\left\{\begin{array}{l}
\sigma_{x}=\frac{\sigma \sqrt{\pi a}}{\sqrt{2 \pi r}} \cos \frac{\theta}{2}\left(1-\sin \frac{\theta}{2} \sin \frac{3 \theta}{2}\right), \\
\sigma_{y}=\frac{\sigma \sqrt{\pi a}}{\sqrt{2 \pi r}} \cos \frac{\theta}{2}\left(1+\sin \frac{\theta}{2} \sin \frac{3 \theta}{2}\right), \\
\tau_{x y}=\frac{\sigma \sqrt{\pi a}}{\sqrt{2 \pi r}} \sin \frac{\theta}{2} \cos \frac{\theta}{2} \cos \frac{3 \theta}{2} .
\end{array}\right.
$$

The stress component in formula (8) could be written as follows:

$$
\sigma_{i j}=K \frac{1}{\sqrt{2 \pi r}} f_{i j}(\theta)
$$

where $K$ is the crack stress intensity factor, which is a function related with loads and geometric dimensions of cracks.

According to formula (8) and the model in Figure 15(b), the stress intensity factor could be expressed as follows:

$$
K=F \sigma \sqrt{\pi a},
$$

where $F$ is the dimensionless stress intensity factor.

According to Bowie's calculation method, $F$ could be expressed as follows:

$$
F=1.12+0.203 \frac{a}{R}-1.197\left(\frac{a}{R}\right)^{2}+1.930\left(\frac{a}{R}\right)^{3} .
$$

5.2. Fracture Toughness Variation Laws under Different Conditions. Under the effects of corrosion and tensile deterioration, the depth $a$ of the surface pit of the sample was measured by using the depth tester. Then, $F$ could be calculated 


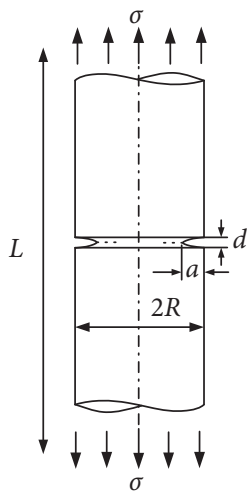

(a)

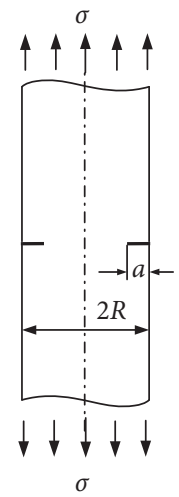

(b)

Figure 15: The mechanical model of tensile fracture of low-carbon steel. (a) The mechanical analysis model. (b) The simplified model.

TABle 3: Crack dimensions and fracture toughness of low-carbon steel under different conditions.

\begin{tabular}{|c|c|c|c|c|c|}
\hline$c(\%)$ & $\sigma_{a}(\mathrm{MPa})$ & $a(\mathrm{~mm})$ & $a / R$ & $F$ & $K\left(\mathrm{MPa} \cdot \mathrm{m}^{-1 / 2}\right)$ \\
\hline \multirow{4}{*}{20} & 0 & 0.122 & 0.0244 & 1.124 & 373.98 \\
\hline & 80 & 0.130 & 0.0260 & 1.125 & 373.17 \\
\hline & 160 & 0.157 & 0.0314 & 1.125 & 373.81 \\
\hline & 240 & 0.224 & 0.0448 & 1.127 & 373.24 \\
\hline \multirow{4}{*}{40} & 0 & 0.126 & 0.0252 & 1.124 & 370.52 \\
\hline & 80 & 0.144 & 0.0288 & 1.125 & 369.72 \\
\hline & 160 & 0.185 & 0.0370 & 1.126 & 369.98 \\
\hline & 240 & 0.247 & 0.0494 & 1.127 & 369.84 \\
\hline \multirow{4}{*}{60} & 0 & 0.138 & 0.0276 & 1.125 & 364.67 \\
\hline & 80 & 0.176 & 0.0352 & 1.126 & 364.57 \\
\hline & 160 & 0.219 & 0.0438 & 1.127 & 364.42 \\
\hline & 240 & 0.263 & 0.0526 & 1.128 & 364.77 \\
\hline \multirow{4}{*}{80} & 0 & 0.146 & 0.0292 & 1.125 & 357.28 \\
\hline & 80 & 0.204 & 0.0408 & 1.126 & 357.08 \\
\hline & 160 & 0.248 & 0.0496 & 1.127 & 356.93 \\
\hline & 240 & 0.324 & 0.0648 & 1.129 & 357.22 \\
\hline
\end{tabular}

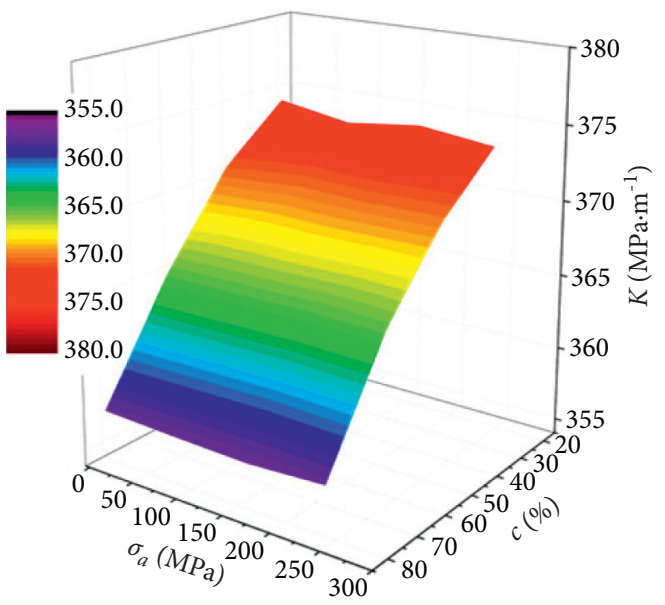

(a)

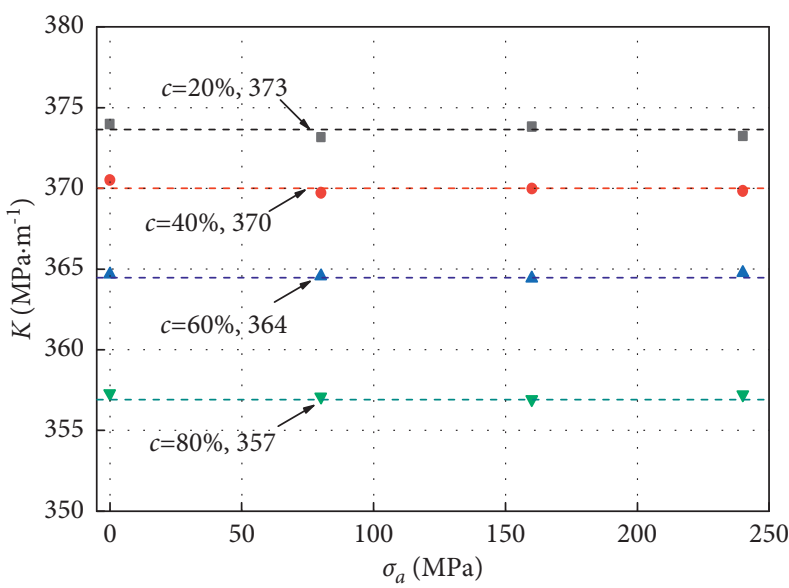

(b)

FIgURE 16: Continued. 


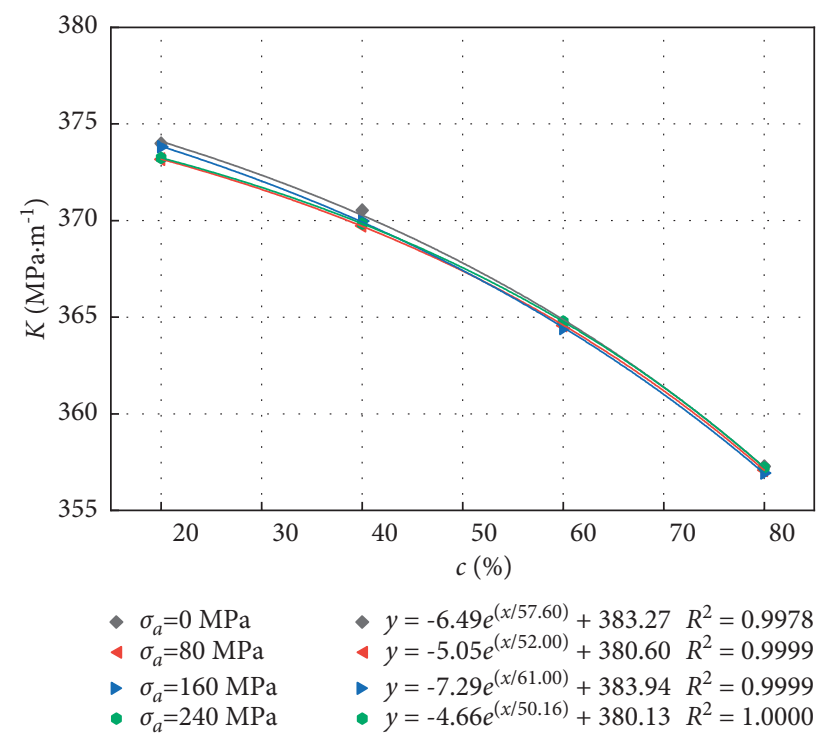

(c)

Figure 16: Variation law of the fracture toughness $(K)$ with the tensile deterioration $\sigma_{a}$ and sea water concentration. (a) Varying surfaces. (b) Tensile deterioration $\sigma_{a}$. (c) Sea water concentration $c$.

by substituting $a$ into formula (11). Then, the fracture toughness $K$ could be obtained under various conditions by substituting the peak stress $\sigma_{b}, F$, and $a$ into formula (10). Table 3 shows the results of each parameter. Based on the data, the change law of $K$ with $\sigma_{a}$ and $c$ could be given, as shown in Figure 16. Based on Table 3 and Figure 16, when $c$ was fixed, the early $\sigma_{a}$ had basically no effects on $K$. When $\sigma_{a}$ was fixed, as $c$ increased, $K$ tended to decrease, showing a negative exponential form. Specifically, when $c$ increased from $20 \%$ to $80 \%, K$ decreased from $373 \mathrm{MPa} \cdot \mathrm{m}^{-1 / 2}$ to $357 \mathrm{MPa} \cdot \mathrm{m}^{-1 / 2}$, decreasing by $4.29 \%$. Moreover, when $c$ was fixed, four curves are basically consist.

Fracture toughness is one of the material's intrinsic properties. It is unrelated to shape and external loading, which has been verified in the test. However, the composition of the low-carbon steel will be changed to a certain degree by the reactions between the elements such as Te and $\mathrm{Cu}$ in low-carbon steel and chemical substances in sea water. This is the root cause of the reduction in fracture toughness of low-carbon steel.

\section{Conclusions}

In this paper, the mechanical properties of the lowcarbon steel were tested in the marine engineering environment by establishing the marine environment simulation test system and conducting tensile tests. The mechanical properties were studied systematically by combining with the microscopic observation of the surface. The fracture mechanism of the low-carbon steel was also studied by constructing the mechanical model. The main conclusions are as follows:
(1) Under the marine engineering environment, as the loading level increased, the mass-loss rate of the lowcarbon steel increased gradually, and it increased fast in a linear form under the effect of the single factor. Both the sea water concentration and tensile deterioration had effects on the mass-loss rate. Meanwhile, the surface roughness also presented similar change characteristics. The analysis of the test data shows that the effect of seawater concentration on the mass loss and surface roughness of low-carbon steel is significantly greater than that of tensile deterioration.

(2) The tensile strength and deformation characteristics of low-carbon steel are significantly affected by seawater concentration and tensile deterioration. The strength characteristic parameters (yield limit and tensile strength) and deformation characteristic parameters (elongation and section shrinkage) show consistent variation with the increase of the loading level, and both show the characteristics of decreasing variation. In addition, the seawater concentration and tensile deterioration have a significant coupling promoting effect on the mechanical property parameters, and the tensile deterioration plays a dominant role in the mechanical property. This was mainly related to the arrangement change of lattice inside the low-carbon steel.

(3) According to tensile mechanical performance of the low-carbon steel, three assumptions of its fracture were proposed. Based on the mechanics of fracture, the tensile fracture mechanical model was established, and the fracture intensity factor was derived 
in the marine engineering environment. Based on the analysis results, the tensile deterioration had no effect on fracture toughness of the low-carbon steel, while the increase of sea water concentration could effectively reduce the fracture toughness.

\section{Data Availability}

The data used to support the findings of this study are included within the article.

\section{Conflicts of Interest}

The authors declare that they have no conflicts of interest.

\section{References}

[1] Y. Ogawa, S. Suzuki, N. Taniguchi, M. Kawasaki, H. Suzuki, and R. Takahashi, "Corrosion resistance of a cast steel overpack for high-level radioactive waste disposal in Japan," Materials and Corrosion, vol. 72, no. 1-2, pp. 52-66, 2020.

[2] M. Mobin and H. Shabnam, "Corrosion behavior of mild steel and SS 304L in presence of dissolved nickel under aerated and deaerated conditions," Materials Research, vol. 14, no. 4, pp. 524-531, 2011.

[3] Z. Zhong, Y. Li, Y. Liu, L. Bao, and Z. Tian, "Cause analysis and mechanism study of cracks in drilling collars," Engineering Failure Analysis, vol. 105, pp. 727-735, 2019.

[4] F. Farhad, D. Smyth-Boyle, X. Zhang, I. Wallis, and D. Panggabean, "Laboratory apparatus for in-situ corrosion fatigue testing and characterisation of fatigue cracks using X-ray micro-computed tomography," Fatigue and Fracture of Engineering Materials and Structures, vol. 41, no. 12, pp. 2629-2637, 2018.

[5] Q. H. Han, X. Wang, and Y. Lu, "Experimental investigation on the corrosion behavior of G20Mn5QT cast steel and butt weld with Q345D steel," Corrosion Science, vol. 132, pp. 194-203, 2018.

[6] W. Zhao, Y. Wang, T. Zhang, and Y. Wang, "Study on the mechanism of high-cycle corrosion fatigue crack initiation in X80 steel," Corrosion Science, vol. 57, pp. 99-103, 2012.

[7] T. Zhao, Z. Liu, C. Du, C. Dai, X. Li, and B. Zhang, "Corrosion fatigue crack initiation and initial propagation mechanism of E690 steel in simulated seawater," Materials Science and Engineering, vol. 708, pp. 181-192, 2017.

[8] S. G. Croll, "Surface roughness profile and its effect on coating adhesion and corrosion protection: a review," Progress in Organic Coatings, vol. 148, Article ID 105847, 2020.

[9] X. Zhang, W. Wei, L. Cheng, J. Liu, K. Wu, and M. Liu, "Effects of niobium and rare earth elements on microstructure and initial marine corrosion behavior of low-alloy steels," Applied Surface Science, vol. 475, pp. 83-93, 2019.

[10] H. C. Ma, Z.Y. Liua, W. Du et al., "Stress corrosion cracking of E690 steel as a welded joint in a simulated marine atmosphere containing sulphur dioxide," Corrosion Science, vol. 100, pp. 627-641, 2015.

[11] D. Arun, R. Vimala, and K. Devendranath Ramkumar, "Investigating the microbial-influenced corrosion of UNS S32750 stainless-steel base alloy and weld seams by biofilm-forming marine bacterium Macrococcus equipercicus," Bioelectrochemistry, vol. 135, Article ID 107546, 2020.

[12] P. J. Antony, R. K. S. Raman, R. Raman, and P. Kumar, "Role of microstructure on corrosion of duplex stainless steel in presence of bacterial activity," Corrosion Science, vol. 52, no. 4, pp. 1404-1412, 2010.

[13] N. Wang, H. Yu, W. Bi, H. Zhu, W. Gong, and Y. Diao, "Effects of coral sand powder and corrosion inhibitors on reinforcement corrosion in coral aggregate seawater concrete in a marine environment," Structural Concrete, pp. 1-15, 2020.

[14] M. A. Daeubler, G. W. Warren, I. M. Bernstein, and A. W. Thompson, "Modeling of corrosion fatigue crack initiation under passive electrochemical conditions," Metall. Trans. A, vol. 22, no. 2, pp. 521-529, 1991.

[15] P. Hu, Q. Meng, W. Hu, F. Shen, Z. Zhan, and L. Sun, “A continuum damage mechanics approach coupled with an improved pit evolution model for the corrosion fatigue of aluminum alloy," Corrosion Science, vol. 113, pp. 78-90, 2016.

[16] X. Zhang, Y. Yu, B. Liu et al., "Y-situ investigation of deformation behavior and fracture mechanism of laminated $\mathrm{Al}$ / Ti composites fabricated by hot rolling," Journal of Alloys and Compounds, vol. 783, pp. 55-65, 2019.

[17] Y. Ding, R. Cao, and Y. Yan, "Effects of heat treatment on fracture mechanism of martensite/austenite MLS composite plates by hot roll bonding," Materials Science and Engineering, vol. 773, Article ID 138727, 2019.

[18] V. N. Khiratkar, K. Mishra, and A. Singh, "Deformation and microstructural evolution of nanostructured pearlite under tension versus torsion," Steel Research International, vol. 2000526, pp. 1-9, 2020.

[19] J. Chen, J. kuan Ren, Z. yu Liu, and G. dong Wang, "The essential role of niobium in high manganese austenitic steel for application in liquefied natural gas tanks," Materials Science and Engineering, vol. 772, Article ID 138733, 2020.

[20] S. Pandre, P. Takalkar, N. Kotkunde, S. K. Singh, and A. U1 Haq, "Influence of temperatures and strain rates on tensile deformation behaviour of DP 590 steel," Mater. Today Proc.vol. 18, pp. 2603-2610, 2019.

[21] Y. Cao, B. Karlsson, and J. Ahlström, "Temperature and strain rate effects on the mechanical behavior of dual phase steel," Materials Science and Engineering, vol. 636, pp. 124-132, 2015.

[22] X. S. Du, Y. J. Su, J. X. Li, L. J. Qiao, and W. Y. Chu, "Stress corrosion cracking of A537 steel in simulated marine environments," Corrosion Science, vol. 65, pp. 278-287, 2012.

[23] X. Huang, "The experimental investigation of stress corrosion for 37CrNi3MoVE steel in artificial Seawater," Master's Thesis, Zhejiang University of Technology, Zhejiang, China, 2012.

[24] S. M. El-Soudani, "Pro_lometric analysis of fractures," Metallography, vol. 11, no. 3, pp. 247-336, 1978. 